Natalia da Mata Luchetti

\title{
Revisão taxonômica do gênero Potamotrygonocestus Brooks \& Thorson, 1976 (Eucestoda: Tetraphyllidea)
}




\section{Revisão taxonômica do gênero Potamotrygonocestus Brooks \& Thorson, 1976 (Eucestoda: Tetraphyllidea)}

\section{Taxonomic revision of the genus Potamotrygonocestus Brooks \& Thorson, 1976 (Eucestoda: Tetraphyllidea)}

Versão corrigida. O original encontra-se disponível no Instituto de Biociências da USP conforme resoluçao CoPGR 5890

Dissertação apresentada ao Instituto de Biociências da Universidade de São Paulo para obtenção do título de Mestre em Ciências Biológicas, na área de Zoologia. Versão aprovada e corrigida de acordo com as sugestões da comissão julgadora em 12 de agosto de 2011, com aval do orientador.

Orientador: Dr. Fernando Portella de Luna Marques 
Luchetti, Natalia da Mata

Revisão taxonômica de Potamotrygonocestus

Brooks \& Thorson, 1976 (Eucestoda, Tetraphyllidea). vi+106p

Dissertação (Mestrado) - Instituto de Biociências da Universidade de São Paulo. Departamento de Zoologia.

1.Helmintologia; 2. Parasitologia; 3. Especificidade; 4. Sistemática; 5. Neotropical

Universidade de São Paulo. Instituto de Biociências

Departamento de Zoologia

\section{Comissão Julgadora}

Prof. Dr. Fernando Portella de Luna Marques (Presidente)

IB-USP

Prof. Dr. Marcelo Knoff

FIOCRUZ

Prof. Dr. Silvio Shigueo Nihei

IB-USP 
Para minha mãe e meus irmãos, por sempre incentivarem minha curiosidade. 


\section{AGRADECIMENTOS}

Tenho uma enorme gratidão à minha mãe, Ana Maria da Mata, e aos meus irmãos, Daniela e Ricardo da Mata Luchetti, por todo o apoio que recebi nos últimos três anos para que eu concluísse mais esta etapa da minha vida, não apenas acadêmica. $\mathrm{O}$ incentivo deles foi extremamente importante em todas as minhas decisões e continua crescendo com o passar do tempo. Sou muito grata aos três por acreditarem em mim, pois sem o seu suporte eu não teria chegado até aqui.

Agradeço a meu orientador, Prof. Dr. Fernando Portella de Luna Marques, por me apresentar o fantástico mundo dos parasitas e por ter me dado a oportunidade de me tornar uma pesquisadora. Tudo que aprendi nestes 7 anos de convivência no laboratório e em coletas certamente não será esquecido.

Aos meus colegas de laboratório, obrigada pela convivência e amizade e por dividirem esta experiência comigo. Mauro Cardoso Jr. e Verônica Mantovani Bueno, que tornaram as longas tardes no laboratório triando válvulas em períodos divertidos e proveitosos e ajudaram bastante nas discussões sobre taxonomia. Marcus Vinícius Domingues pelo apoio na preparação do projeto deste mestrado e por compartilhar seu conhecimento em taxonomia e experiência acadêmica. Laura Raldi Canal, por todas as conversas dentro e fora do laboratório e por ter sido uma ótima aluna de IC, pois ensinar foi um dos meus maiores aprendizados. Felipe Martins por sua ajuda na fase final deste projeto e pelos conselhos, acadêmicos ou não. Francisco Cádiz por estar sempre pronto a ajudar e por seu apoio na fase final deste projeto.

Agradeço ao Prof. Dr. Marcelo Rodrigues de Carvalho pela disponibilidade todas as vezes que surgiram dúvidas sobre a taxonomia dos hospedeiros e aos membros do Laboratório de Taxonomia e Sistemática de Elasmobrânquios João Paulo Capretz Batista da Silva e Thiago Loboda por identificarem espécimes e disponibilizarem literatura relacionada a potamotrigonídeos.

Agradeço aos técnicos do Laboratório de Histologia do Departamento de Zoologia IB-USP, Ênio Matos e Phillip Lenktaitis por todo o auxílio com técnicas histológicas e de microscopia eletrônica de varredura e por todos os momentos de descontração que tornaram estas atividades mais agradáveis.

À Profa. Dra. Elisabeth Höfling, última chefe do Departamento de Zoologia IB-USP, e ao Prof. Dr. Alberto de Freitas Ribeiro, coordenador do Laboratório de Biologia Celular e Microscopia Eletrônica e Confocal IB-USP, agradeço pela oportunidade de manusear o microscópio eletrônico de varredura. Ao técnico Márcio Valentim Cruz, do Laboratório de Biologia Celular e Microscopia Eletrônica e Confocal IBUSP, agradeço pela paciência em me ensinar a utilizar o microscópio eletrônico de varredura e por me auxiliar em seu manuseio sempre que necessário.

Agradeço aos curadores das coleções de referência que me enviaram espécimes prontamente sempre que solicitei: Dr. Eric P. Hoberg, da United States National Parasite Collection, e Dr. Marcelo Knoff, da Coleção Helmintológica do Instituto Oswaldo Cruz. Agradeço também ao técnico Eric Gonçalves, do Museu de Zoologia da USP, que me recebeu quando fui buscar espécimes lá depositados. Agradeço a Dra. Janine Caira (University of Connecticut, EUA) pelo empréstimo de espécimes de Potamotrygonocestus de sua coleção pessoal e ao Dr. Florian Reyda (State University of New York College at Oneonta, EUA) pela amizade e por enviar espécimes coletados durante seu doutorado. 
Agradeço a Domingo Rodriguez Fernandez e Sandro Heil, da Divisão de Reservatório da Itaipu Binacional, por possibilitar a coleta de potamotrigonídeos na área da represa de Itaipu, acompanhando a coleta e disponibilizando meios e locais de trabalho.

Às secretárias do Departamento de Zoologia IB-USP, Luzinéia Ongaro Junquer, Maria Lúcia Vieira e Marly Salviano de Almeida, agradeço pelo apoio em diversos momentos deste projeto e pelas muitas balinhas. Aos funcionários da secretaria de pós-graduação IB-USP, Cynthia Helena Dibbern, Erika Harumi Takamoto, Helder Souza, Roberta Dalarme e Vera Lúcia Lima, agradeço por sanar muitas dúvidas durante estes anos.

Aos amigos que fiz no Departamento de Zoologia durante estes anos, agradeço pelos momentos de descontração, nem que fosse apenas na hora do café: Ênio Matos, Felipe Martins, Francisco Cádiz, João Paulo Capretz, José Eduardo Marian, Laura Canal, Marcus Vinícius Domingues, Mauro Cardoso Jr., Thiago Loboda, Tiago Sobreira, Roberta Figueiredo e Verônica Bueno. Aos Profs. Luis Fábio Silveira e Ricardo Pinto da Rocha, agradeço não apenas pela amizade, mas pelo apoio e incentivo durante o desenvolvimento deste projeto.

Sou grata aos amigos que dividiram comigo todas as dúvidas e certezas que tive nos últimos três anos, além de muitas risadas. Manter uma vida fora da academia foi muito importante para ter equilíbrio e lidar com todos os desafios dos últimos anos. Entre os muitos amigos que me apoiaram, agradeço especialmente a Marie Claire Chelini e Thaís Almeida Valvassoura, sempre presentes quando precisei.

Finalmente, quero agradecer ao meu namorado, Ricardo Pereira, pelo amor, carinho, suporte e, principalmente, paciência que recebi durante o desenvolvimento deste estudo. Seu incentivo em momentos em que eu não acreditava que fosse possível chegar ao fim foi imprescindível para que este trabalho fosse concluído.

A realização deste trabalho foi possível devido ao financiamento direto do CNPq na forma de bolsa de mestrado (Proc. no. 134438/2008-6) a N.M.L. e aos auxílio individuais à pesquisa financiados pela FAPESP (Proc. no. 2003/01816-2, 2005/01299-3 e 2008/09436-8. ) a F.P.L.M.. 


\section{ÍNDICE}

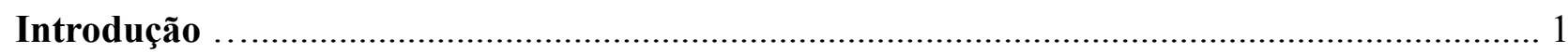

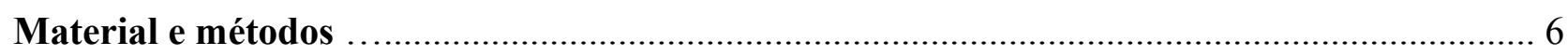

Coleta e processamento do material biológico ........................................................... 6

Material tipo, vouchers e espécimes adicionais .............................................................. 10

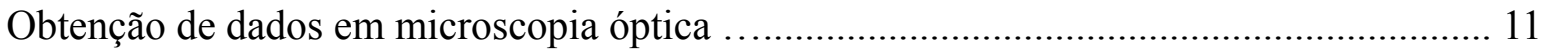

Obtenção de dados em microscopia eletrônica de varredura ............................................. 11

Depósito em coleção de referência .................................................................................... 14

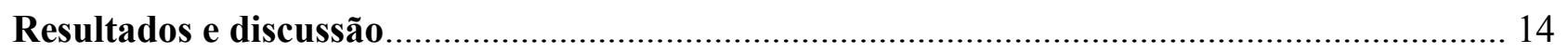

Processamento do material biológico e obtenção de helmintos ....................................... 14

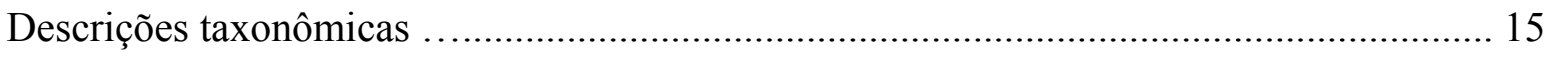

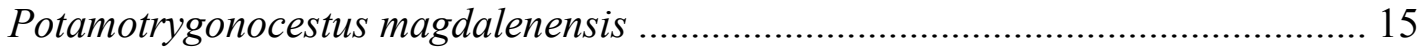

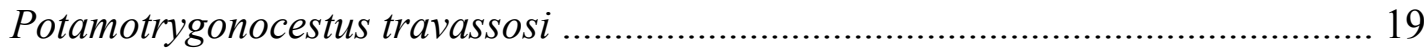

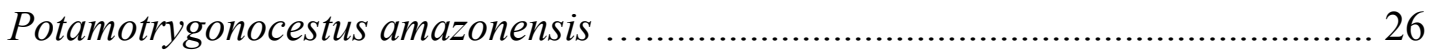

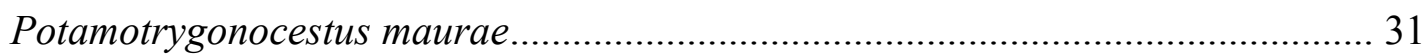

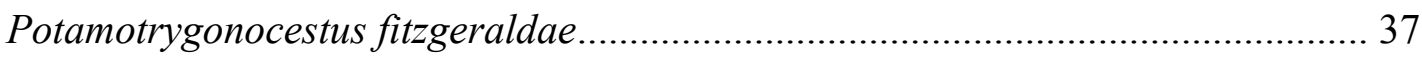

Potamotrygonocestus chaoi ......................................................................... 46

Potamotrygonocestus marajoara …..................................................................... 49

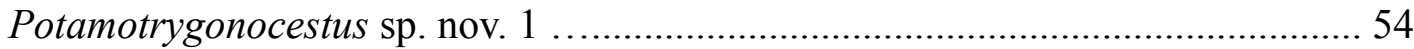

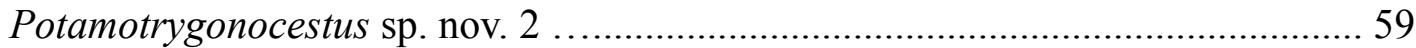

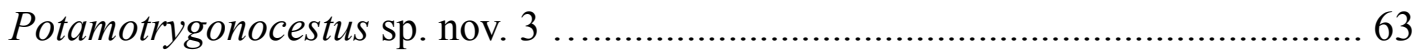

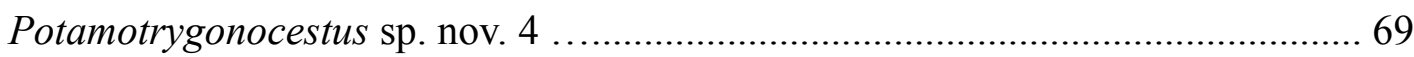

Chave de identificação para espécies do gênero Potamotrygonocestus ............................ 75

Delimitação de espécies em Potamotrygonocestus ...................................................... 76

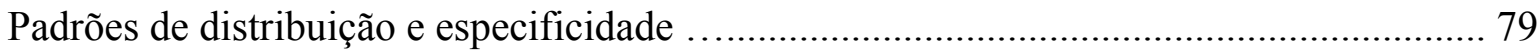

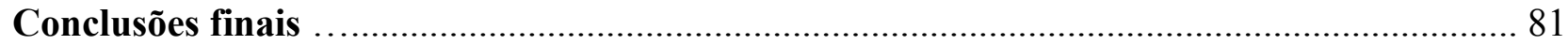

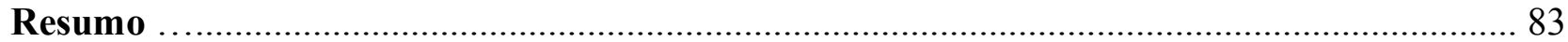

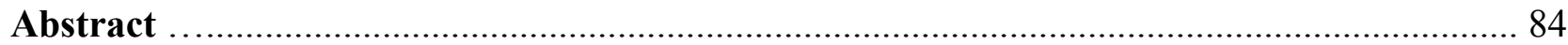

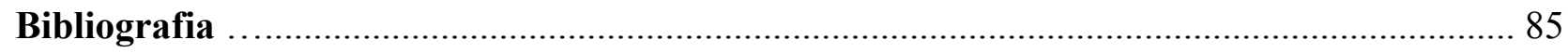

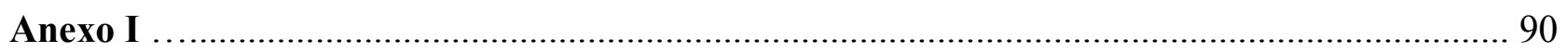

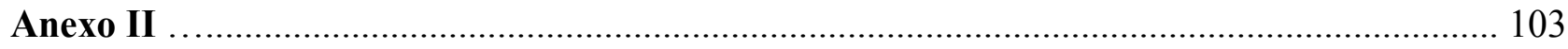




\section{INTRODUÇÃO}

A taxonomia de diversos parasitas é geralmente baseada no conceito tipológico (ou morfológico) de espécie, uma vez que conceitos de espécies gerados a partir de estudos com vertebrados (e.g. Espécie Biológica segundo Mayr, 1963; Mate Recognition System segundo Paterson, 1973, 1978, 1980) não parecem ser amplamente apropriados para este grupo (Kunz, 2002; McCoy, 2003). Para as linhagens de Platyhelminthes parasitas a aplicação deste conceito tipológico é amplamente utilizada, apesar das dificuldades resultantes da fixação de espécimes e da delimitação de estruturas que dependem da flexibilidade da estrutura corpórea destes animais (Mariaux, 1996; Du Preez \& Maritz, 2006). A restrição do número de caracteres morfológicos disponíveis nesses organismos (Criscione et al., 2005) combinada com a ausência de estruturas esclerotizadas que mantenham a forma do corpo constante resulta em diagnoses de grupos baseadas em caracteres plásticos. Assim, a delimitação de táxons para estes parasitas não é feita de maneira precisa, necessitando constante revisão.

Entre os platelmintos que exibem modo de vida parasitário, encontramos os membros de Cestoda. Conhecidos popularmente como solitárias, esses platelmintos são parasitas obrigatórios do trato digestivo de vertebrados quando adultos, embora seus estágios larvais ocorram em diversos grupos de invertebrados e vertebrados (Stunkard, 1953). As solitárias são conhecidas há milhares de anos (Hyman, 1951; Stunkard, 1962; Roberts \& Janovy Jr., 1996) e diversos estudos documentam sua diversidade e relações de parentesco (e.g. Brooks et al., 1981; Hoberg et al., 1997; Mariaux, 1998; Hoberg et al., 1999; Olson et al., 2001; Waeschenbach et al., 2007; Healy et al., 2009; entre outros). Tradicionalmente, a taxonomia dos cestóideos é baseada em caracteres morfológicos (e.g. Euzet, 1994; Mariaux, 1996; Caira et al., 1999) e por isso sofre com delimitações de táxons não acuradas que podem não refletir grupos monofiléticos. Um exemplo desta prática é a ordem Tetraphyllidea Carus, 1863.

A ordem Tetraphyllidea apresenta a maior diversidade morfológica entre as solitárias. A maioria de seus adultos é essencialmente parasita de válvulas espirais de elasmobrânquios (Roberts \& Janovy Jr., 1996; Caira et al., 1999; Caira \& Jensen, 2001). São conhecidas cerca de 800 espécies inseridas em 65 gêneros e em 8 famílias (Euzet, 1994; Caira et al., 2006). A definição de gêneros e espécies dos membros desta ordem é historicamente baseada em observações nos indivíduos adultos (e.g. Euzet, 1994; Caira et al, 1999), pois não há ciclo de vida completo conhecido para nenhum de seus táxons (Caira \& Reyda, 2005; Jensen \& Bullard, 2010). Revisões recentes para o grupo (e. g. Caira et al., 1999; Hoberg et al., 1999; Olson et al., 2001; Waeschenbach et al., 2007; Healy et al., 2009) indicam a parafilia do táxon, independente se baseadas em técnicas morfológicas ou 
moleculares. Esta parafilia pode ser resultante das práticas tradicionais de diagnose destes parasitas (i.e. baseadas em caracteres plásticos e inconsistentes) e requer refinamento dos táxons.

Aproximadamente metade das espécies de tetrafilídeos conhecidas está inserida na família Onchobothriidae (Caira et al., 2006). Os membros desta família são prontamente reconhecidos por possuir ganchos esclerotizados em suas escóleces (Caira \& Jensen, 2001) e estão divididos em 16 gêneros (Euzet, 1994; Caira \& Jensen, 2009). Parasitas exclusivos de elasmobrânquios (Caira \& Jensen, 2001), os oncobotriídeos são essencialmente marinhos, exceto os representantes do gênero Potamotrygonocestus. Indivíduos pertencentes a este gênero são parasitas exclusivos de raias da família Potamotrygonidae, endêmica dos sistemas fluviais da América do Sul (Lovejoy et al., 1998; Carvalho et al., 2003; Carvalho \& Lovejoy, 2011) e são reconhecidos pela morfologia exclusiva de seus ganchos simples (Figura 1A, B), células glandulares ao redor do vaso deferente (Figura 1C) e testículos anteriores ao ovário (Figura 1A, C) (Marques et al., 2003). Espécimes de Potamotrygonocestus apresentam estróbilo acraspédoto, hiperapolítico (Figura 1A); quatro botrídeos sésseis não septados, cada um com uma ventosa apical e um par de ganchos simples (Figura 1B); poro genital postero-lateral alternado irregularmente (Figura 1A, C), vagina anterior ao saco do cirro (Figura 1C); testículos em duas fileiras anteriores ao ovário, vitelária lateral aos testículos, ovário posterior, bilobado em cortes histológicos e útero em forma de saco (Figura 1C). Sua estrutura corpórea é simples e é a base de sua taxonomia, já que não há estudos publicados fundamentados em outras fontes de dados (i.e. moleculares ou ecológicos). Tem-se, portanto, a delimitação de espécies para Potamotrygonocestus sujeita a artefatos de preparação, o que faz necessária a revisão de seus parâmetros taxonômicos para a diagnose precisa dos táxons.

O gênero Potamotrygonocestus foi proposto recentemente e possui um histórico taxonômico simples. Brooks \& Thorson (1976) o propuseram para receber P. magdalenensis, parasita de Potamotrygon magdalenae, endêmica do sistema Magdalena-Atrato na Colômbia. Potamotrygonocestus travassosi foi descrita três anos depois (Rego, 1979), seguida por $P$. amazonensis (Mayes, Brooks \& Thorson, 1981). A primeira revisão taxonônomica para este gênero incluiu uma nova espécie, P. orinocoensis Brooks Mayes \& Thorson, 1981, mas Marques et al. (2003) a consideraram sinonímia júnior de $P$. travassosi e acrescentaram 3 outras espécies ao gênero: $P$. chaoi, P. fitzgeraldae e $P$. maurae. O mais recente trabalho para o gênero foi feito por Luchetti et al. (2008), com a redescrição de $P$. chaoi e a descrição de uma nova espécie, $P$. marajoara, parasita de Plesiotrygon iwamae. Assim, Potamotrygonocestus é representado por 7 espécies válidas. Embora o gênero tenha sido revisto recentemente, ainda restam inconsistências relacionadas à circunscrição e número de linhagens que o compõe, pois há indícios de novas espécies de Potamotrygonocestus na revisão sistemática de Marques et al. (2003), na qual os 


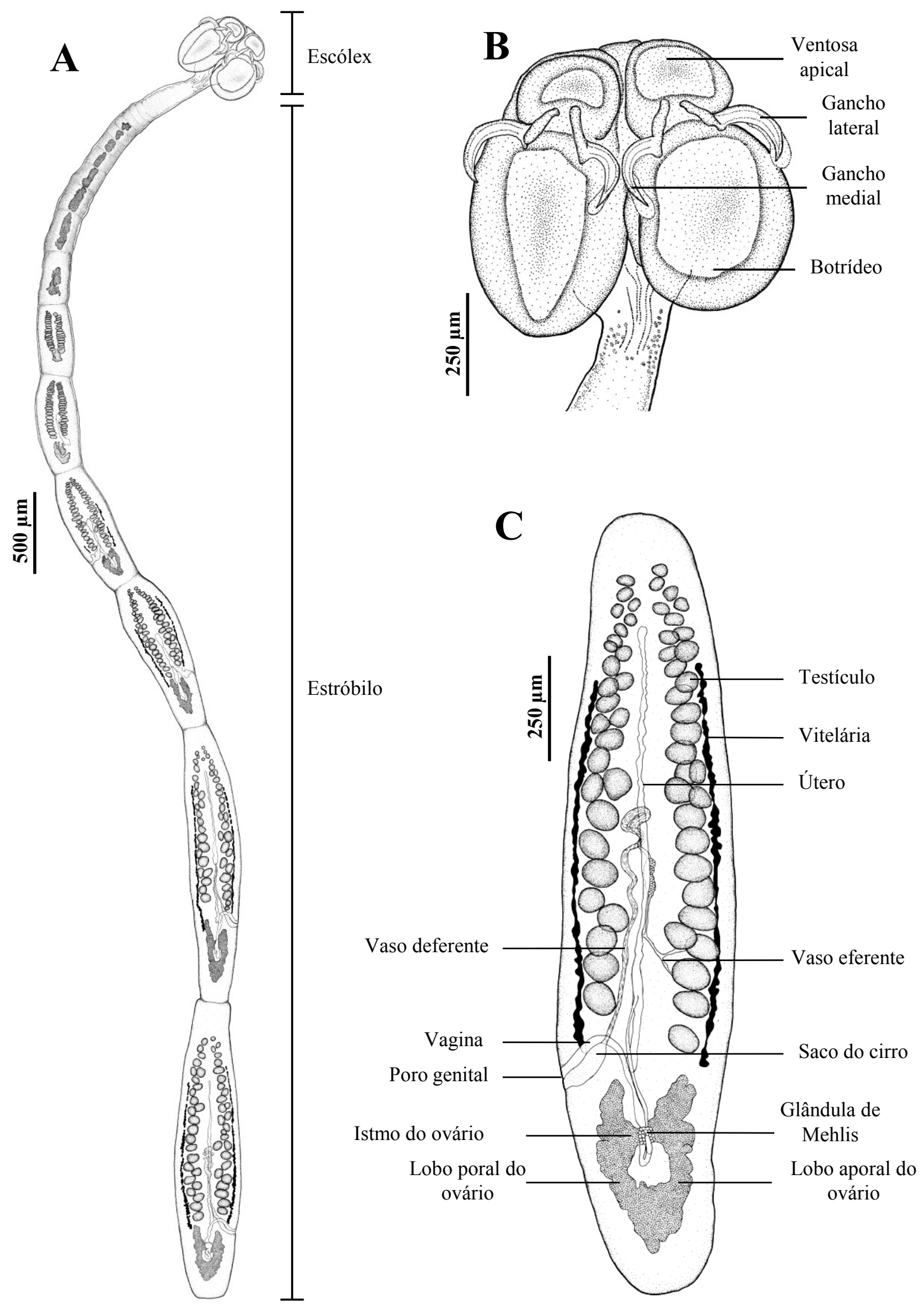

Figura 1. Morfologia geral de Potamotrygonocestus ssp. A: espécime adulto completo (MZUSP 6387). B. Escólex (MZUSP 6387). C: proglótide madura (MZUSP 6388b). (Fonte: modificado de Luchetti et al., 2008). 
autores citam, sem descrever, duas possíveis linhagens.

A taxonomia do gênero Potamotrygonocestus sempre foi baseada principalmente em caracteres merísticos e morfométricos (Brooks \& Thorson, 1976; Rego, 1979; Mayes et al., 1981; Marques et al., 2003; Luchetti et al., 2008). A primeira chave de identificação proposta para o gênero (Brooks et al., 1981) foi baseada no comprimento dos ganchos e na morfologia da vitelária, porém a validade diagnóstica destes caracteres foi questionada por Marques et al. (2003), que observaram variação no comprimento dos ganchos em populações diferentes de uma mesma espécie (e.g. P. travassosi) e dependência do estágio de desenvolvimento para determinar a morfologia da vitelária. Os autores propuseram uma nova chave de identificação com dados discretos, como simetria dos ganchos, porém ainda utilizaram caracteres merísticos para diagnosticar espécies, como número de testículos, prática seguida por Luchetti et al. (2008). Apesar do incremento que Marques et al. (2003) propuseram para a taxonomia de Potamotrygonocestus, os problemas referentes à fixação dos espécimes persistiram, já que a diagnose de espécies permaneceu baseada em caracteres morfologicamente variáveis.

A maioria das espécies de Potamotrygonocestus foi descrita com base em um número restrito de exemplares coletados em localidades geograficamente isoladas e distantes, geralmente provindos de poucos espécimes de hospedeiros. Esta prática pode ser exemplificada por $P$. travassosi e P. amazonensis, que tem suas descrições baseadas em 5 espécimes cada, de um número indeterminado de hospedeiros coletados em apenas uma localidade (Rego, 1979; Mayes et al., 1981). O isolamento e distância geográfica das coletas em que Potamotrygonocestus foram amostrados podem ser a causa da baixa variação morfológica observada em cada linhagem de parasitas. O esforço amostral feito por Marques et al. (2003) buscou resolver este problema, porém a subamostragem de algumas regiões geográficas (e.g. região hidrográfica do Paraná-Paraguai) fez com que algumas populações de parasitas permanecessem pouco representadas. A descrição de $P$. marajoara (Luchetti et al., 2008) foi uma exceção para o gênero em relação ao número de helmintos examinados, porém a restrição geográfica de coleta dos hospedeiros (todos provenientes de uma mesma localidade) comprometeu o estudo de uma possível variabilidade intraespecífica dos parasitas.

A consistência dos caracteres utilizados na taxonomia de Potamotrygonocestus nunca foi objeto de discussão em nenhum estudo que abordou o gênero. A definição dos caracteres diagnósticos utilizados e sua importância na delimitação das espécies do gênero seguem a diagnose proposta por Brooks \& Thorson (1976) e foram ratificadas na revisão de Marques et al. (2003). O emprego dos caracteres merísticos e morfométricos tradicionalmente utilizados admite a inexistência de influência de fatores ecológicos na morfologia destes organismos, prática que deve 
ser revista devido ao estudo de Randhawa \& Poulin (2009). Estes autores mostraram que fatores ecológicos externos influenciam a morfologia de tetrafilídeos, indicando que populações de hospedeiros distintas podem gerar diferenças intraespecíficas nos parasitas. A partir deste estudo, podemos esperar que a ampliação da representatividade biogeográfica das coletas de Potamotrygonocestus permita compreender melhor variabilidade intraespecífica para estes parasitas, o que resultaria na necessidade de redefinição de seus caracteres diagnósticos.

Além de helmintos do gênero Potamotrygonocestus, outras linhagens de cestóideos podem ser encontradas parasitando potamotrigonídeos: Acanthobothrium Van Beneden, 1850; Rhinebothrium Linton 1890; Rhinebothroides Mayes, Brooks \& Thorson, 1981; Paraoncomegas Campbell, Marques \& Ivanov, 1999; Anindobothrium Marques, Brooks \& Lasso, 2001 e Nandocestus Reyda, 2008 (Marques, 2000; Reyda, 2008). Recentemente, revisões taxonômicas para Acanthobothrium (Cardoso Jr., 2010), Rhinebothrium (Reyda \& Marques, 2011) e Rhinebothroides (Bueno, 2010) buscaram o refinamento da taxonomia destes gêneros. Estes trabalhos mostraram que o aumento do número de espécimes examinados, provenientes de localidades amplamente distribuídas e diferentes daquelas onde foram coletados os tipos apresentam grande diversidade morfológica, sendo necessário o emprego de caracteres discretos para a diagnose dos táxons. O refinamento taxonômico apresentado por estes autores também possibilitou que as relações de especificidade parasita-hospedeiro para Acanthobothrium, Rhinebothrium e Rhinebothroides parasitas de potamotrigonídeos fossem revistas, uma vez que a identificação correta dos táxons envolvidos (parasitas e hospedeiros) é essencial para o sucesso destes estudos (Poulin \& Morand, 2000; Caira \& Jensen, 2001; Reyda \& Marques, 2011).

Cestóideos pertencentes à ordem Tetraphyllidea tem sido considerados, por muito tempo, especialistas ou oioxenos (e.g. Williams 1964, 1966, 1968), dentre os quais os membros de Onchobothriidae são apontados como exemplos clássicos deste padrão de especificidade aos seus hospedeiros (Caira \& Jensen, 2001). Baseados em sistemas marinhos, os estudos sobre especificidade estrita parecem não ser aplicáveis aos sistemas fluviais que abrigam potamotrigonídeos. Marques et al. (2003) e Marques \& Brooks (2003) documentaram que algumas espécies dos gêneros Potamotrygonocestus e Rhinebothroides são generalistas, porém com a ressalva de que esta condição poderia ser decorrente de falhas na identificação de espécies tanto de parasitas como de hospedeiros, o que tornaria necessária a revisão taxonômica de ambos. Os trabalhos de Cardoso Jr. (2010), Reyda \& Marques (2011) e Bueno (2010) mostraram que o refinamento taxonômico dos parasitas confirma o que havia sido documentado por aqueles autores. Baseado nas revisões destes autores, é esperado que o refinamento taxonômico do gênero Potamotrygonocestus também possa elucidar suas relações de especificidade com seus hospedeiros, 
confirmando ou não sua generalidade.

A sugestão de possíveis complexos de espécies devido a subamostragem de regiões biogeográficas como a bacia do Prata e a citação de linhagens não descritas (Marques et al., 2003) para o gênero Potamotrygonocestus indicam a necessidade de refinamento na taxonomia do grupo. A delimitação de espécies de maneira não ambígua e independente da fixação dos espécimes é necessária para o gênero, pois assim será possível determinar a relevância da influência de fatores ecológicos na morfologia deste táxon. Além disso, a diagnose inequívoca das espécies de Potamotrygonocestus baseada em amostras mais representativas também se faz necessária para esclarecer as relações destes parasitas com seus hospedeiros, conforme foi observado recentemente para outras linhagens de parasitas de potamotrigonídeos (Cardoso Jr., 2010; Reyda \& Marques, 2011 e Bueno, 2010). Diante deste contexto, este estudo busca refinar a taxonomia do grupo e elucidar as relações destes parasitas com seus hospedeiros, compreendendo melhor a sistemática deste componente de nossa fauna.

\section{MATERIAIS E MÉTODOS}

\section{Coleta e processamento do material biológico}

Os potamotrigonídeos amostrados neste estudo foram coletados entre 1995 e 2009, utilizando métodos de captura como espinhéis, arpões e redes de arrasto. No total, foram obtidos 1060 espécimes pertencentes à família Potamotrygonidae representando 32 espécies potencialmente distintas, sendo que 16 espécies ainda devem ser formalmente descritas. Os potamotrigonídeos coletados foram identificados durante a coleta ou por fotografias pelo Dr. Fernando P. L. Marques e por membros do Laboratório de Taxonomia e Sistemática de Elasmobrânquios do Departamento de Zoologia do Instituto de Biociências da USP, sob coordenação do Dr. Marcelo Rodrigues de Carvalho. Os nomes atribuídos a hospedeiros não descritos seguem Marques \& Domingues (2006). As coletas de hospedeiros abrangem 11 bacias hidrográficas da América do Sul, denominadas Alto Amazonas, Baixo Amazonas, Negro-Branco, Purus, Madeira, Tapajós, Xingu, Parnaíba, TocantinsAraguaia, Paraná-Paraguai e Uruguai. A representatividade de hospedeiros e suas localidades de coleta estão listadas na Tabela 1 e representadas na Figura 2.

Os hospedeiros coletados foram anestesiados com solução saturada de benzocaína em etanol 92\% injetada na região cardíaca ou com dissolução do anestésico na água do tanque em que estavam após a captura. Após a eutanásia, as válvulas espirais dos espécimes foram removidas, abertas longitudinalmente e àquelas destinadas a estudos de morfologia de parasitas foram fixadas em formalina $4 \%$ a $60^{\circ} \mathrm{C}$. Em laboratório, estas válvulas foram transferidas para etanol $70 \%$ e triadas sob estereoscópio para a remoção de parasitas, mantidos em etanol 70\%. 
Tabela 1. Locais de coleta e hospedeiros amostrados para Potamotrygonocestus. ${ }^{*}$

\begin{tabular}{|c|c|c|c|c|c|}
\hline Bacia hidrográfica & Rio & Município, Estado, País & Localidade geográfica & Espécie & Data \\
\hline \multirow[t]{10}{*}{ Paraná/Paraguai } & Rio Paraná & Puerto Reconquista, Santa Fé, Argentina & $\mathrm{S} 29^{\circ} 13^{\prime}, \mathrm{O} 59^{\circ} 34^{\prime}$ & Potamotrygon motoro & Fevereiro, 1995 \\
\hline & Rio Paraná, jusante da UHE Porto Primavera & Rosana, SP, Brasil & $\mathrm{S} 22^{\circ} 28^{\prime} 43.31^{\prime \prime}, \mathrm{O} 52^{\circ} 58^{\prime} 26.04^{\prime \prime}$ & Potamotrygon motoro & Abril, 2004 \\
\hline & Rio Paraná, jusante da UHE Itaipu & Foz do Iguaçu, PR, Brasil & S $25^{\circ} 24^{\prime} 45.96^{\prime \prime}, \mathrm{O} 54^{\circ} 35^{\prime} 39.24^{\prime \prime}$ & Potamotrygon falkneri & Abril, 2004 \\
\hline & Rio Paraná, canal do lago principal da UHE Itaipu & Foz do Iguaçu, PR, Brasil & $\mathrm{S} 25^{\circ} 24^{\prime} 45.96^{\prime \prime}, \mathrm{O} 54^{\circ} 35^{\prime} 39.24^{\prime \prime}$ & Potamotrygon motoro & Outubro, 2009 \\
\hline & Rio Apa & Bela Vista, MS, Brasil & $\mathrm{S} 22^{\circ} 11^{\prime}, \mathrm{O} 56^{\circ} 51^{\prime}$ & Potamotrygon falkneri & Julho, 1996 \\
\hline & Rio Paraguai & Corumbá, MS, Brasil & S $19^{\circ} 20^{\prime} 53.15^{\prime \prime}, \mathrm{O} 57^{\circ} 19^{\prime} 11.28^{\prime \prime}$ & Potamotrygon motoro & Dezembro, 2003 \\
\hline & & & & Potamotrygon falkneri & \\
\hline & Rio Paraguai, Igarapé Padre Inácio & Cáceres, MT, Brasil & S $16^{\circ} 14^{\prime} 27.63^{\prime \prime}$, O $57^{\circ} 47^{\prime} 8.92^{\prime \prime}$ & $\begin{array}{l}\text { Potamotrygon motoro } \\
\text { Potamotrygon } \mathrm{sp}\end{array}$ & Junho, 2007 \\
\hline & Rio Salobra & Miranda, MS, Brasil & S $20^{\circ} 12^{\prime} 59.34^{\prime \prime}, \mathrm{O} 56^{\circ} 29^{\prime} 42.95^{\prime \prime}$ & $\begin{array}{l}\text { Potamotrygon motoro } \\
\text { Potamotrygon falkneri } \\
\text { Potamotrygon histrix } \\
\text { Potamotrygon cf. motoro }\end{array}$ & Julho, 2004 \\
\hline & Rio Cuiabá, Rio Mutum & Barão de Melgaço, MT, Brasil & $\mathrm{S} 16^{\circ} 17^{\prime} 55^{\prime \prime}, \mathrm{O} 55^{\circ} 48^{\prime} 13.31^{\prime \prime}$ & $\begin{array}{l}\text { Potamotrygon motoro } \\
\text { Potamotrygon brachyura } \\
\text { Potamotrygon cf. motoro }\end{array}$ & Julho, 2006 \\
\hline Uruguai & Rio Uruguai & Porto Xavier, RS, Brasil & S $27^{\circ} 53^{\prime} 44.75^{\prime \prime}$, O $55^{\circ} 13^{\prime} 29.78^{\prime \prime}$ & Potamotrygon brachyura & Março, 2005 \\
\hline \multirow[t]{2}{*}{ Baixo Amazonas } & Baía de Marajó, Rio Tocantins & Colares, PA, Brasil & S $0^{\circ} 55^{\prime} 34.68^{\prime \prime}, \mathrm{O} 48^{\circ} 17^{\prime} 25.43^{\prime \prime}$ & $\begin{array}{l}\text { Plesiotrygon iwamae } \\
\text { Paratrygon aiereba } \\
\text { Potamotrygon scobina } \\
\text { Potamotrygon orbignyi }\end{array}$ & $\begin{array}{l}\text { Novembro, } 2003 \\
\text { Agosto, } 2007\end{array}$ \\
\hline & Baía de Marajó, Rio Arari, Igarapé Urubu & Cachoeira do Arari, PA, Brasil & S $0^{\circ} 59^{\prime} 58.20^{\prime \prime}, \mathrm{O} 48^{\circ} 57^{\prime} 52.55^{\prime \prime}$ & $\begin{array}{l}\text { Potamotrygon motoro } \\
\text { Potamotrygon sp mar1 }\end{array}$ & Agosto, 2007 \\
\hline \multirow[t]{4}{*}{ Tocantins-Araguaia } & Rio Paranã & Paranã, TO, Brasil & $\mathrm{S} 12^{\circ} 37^{\prime} 34.38^{\prime \prime}, \mathrm{O} 47^{\circ} 52^{\prime} 55.47^{\prime \prime}$ & $\begin{array}{l}\text { Paratrygon aiereba } \\
\text { Potamotrygon orbignyi } \\
\text { Potamotrygon } \mathrm{sp} \_ \text {toc } 1\end{array}$ & Julho, 2004 \\
\hline & Rio Araguaia & Caseara, TO, Brasil & S 9 16' 11.66", O 49 58' 18.70" & $\begin{array}{l}\text { Paratrygon aiereba } \\
\text { Potamotrygon orbignyi } \\
\text { Potamotrygon } \mathrm{sp}_{-} \text {toc } 4 \\
\text { Potamotrygon henlei }\end{array}$ & Junho, 2005 \\
\hline & Rio Tocantins & Ipueiras, TO, Brasil & 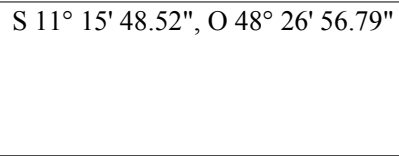 & $\begin{array}{l}\text { Potamotrygon } \mathrm{cf} . \text { scobina } \\
\text { Potamotrygon } \mathrm{cf} \text {. orbignyi } \\
\text { Potamotrygon } \mathrm{sp} \text {.toc } 2 \\
\text { Potamotrygon } \mathrm{sp} \text {-toc } 3\end{array}$ & Junho, 2005 \\
\hline & Rio Tocantins & Marabá, PA, Brasil & $\mathrm{S} 3^{\circ} 37^{\prime}, \mathrm{O} 60^{\circ} 23^{\prime}$ & Potamotrygon henlei & Setembro, 1996 \\
\hline \multirow[t]{3}{*}{ Baixo Amazonas } & Rio Amazonas & Belém, PA, Brasil & 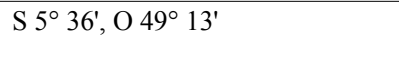 & $\begin{array}{l}\text { Paratrygon aiereba } \\
\text { Potamotrygon constellata }\end{array}$ & Setembro, 1996 \\
\hline & Confluência do Paraná Janauacá e Rio Solimões & Manaus, AM, Brasil & $\mathrm{S} 3^{\circ} 37^{\prime}, \mathrm{O} 60^{\circ} 23^{\prime}$ & $\begin{array}{l}\text { Plesiotrygon iwamae } \\
\text { Potamotrygon scobina }\end{array}$ & Outubro, 1996 \\
\hline & Rio Solimões & Manaus, AM, Brasil & $\mathrm{S} 3^{\circ} 37^{\prime}, \mathrm{O} 60^{\circ} 23^{\prime}$ & Potamotrygon motoro & Outubro, 1996 \\
\hline
\end{tabular}


Tabela 1. Locais de coleta e hospedeiros amostrados para Potamotrygonocestus.*

\begin{tabular}{|c|c|c|c|c|c|}
\hline Bacia hidrográfica & Rio & Município, Estado, País & Localidade geográfica & Espécie & Data \\
\hline \multirow[t]{5}{*}{ Alto Amazonas } & Rio Solimões, Ilha do Aramaça & Tabatinga, AM, Brasil & 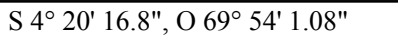 & Potamotrygon motoro & Setembro, 2006 \\
\hline & & & & Potamotrygon cf. motoro & \\
\hline & & & & Potamotrygon sp 1 & \\
\hline & & & & Potamotrygon sp 3 & \\
\hline & Rio Javari & Benjamin Constant, AM, Brasil & $\mathrm{S} 4^{\circ} 18^{\prime} 15.11 ", \mathrm{O} 70^{\circ} 4^{\prime} 19.56^{\prime \prime}$ & Paratrygon aiereba & Setembro, 2006 \\
\hline \multirow[t]{4}{*}{ Xingu } & Rio Xingu & Altamira, PA, Brasil & $\mathrm{S} 3^{\circ} 21^{\prime}, \mathrm{O} 52^{\circ} 20^{\prime}$ & Potamotrygon leopoldi & Outubro, 1996 \\
\hline & Rio Xingu & São Félix do Xingu, PA, Brasil & S 6 39' 23.33", O 51 59' 56.72" & Paratrygon aiereba & Julho, 2005 \\
\hline & & & & Potamotrygon orbignyi & \\
\hline & & & & Potamotrygon leopoldi & \\
\hline \multirow[t]{9}{*}{ Tapajós } & Rio Tapajós & Itaituba, PA, Brasil & S 4 $4^{\circ} 36^{\prime} 29.87^{\prime \prime}, \mathrm{O} 56^{\circ} 16^{\prime} 22.8^{\prime \prime}$ & Paratrygon aiereba & Outubro, 2005 \\
\hline & Rio Tapajós & Santarém, PA, Brasil & $\mathrm{S} 2^{\circ} 17^{\prime} 3.84^{\prime \prime}, \mathrm{O} 55^{\circ} 0^{\prime} 13.67^{\prime \prime}$ & Paratrygon aiereba & Outubro, 2005 \\
\hline & & & $\mathrm{S} 4^{\circ} 36^{\prime} 29.87^{\prime \prime}, \mathrm{O} 56^{\circ} 16^{\prime} 22.80^{\prime \prime}$ & Potamotrygon orbignyi & \\
\hline & & & & Potamotrygon humerosa & \\
\hline & & & & Potamotrygon motoro & \\
\hline & & & & Potamotrygon cf. motoro & \\
\hline & & & & Potamotrygon $\mathrm{sp} \_\mathrm{tpj} 1$ & \\
\hline & Rio Teles Pires & Apiacás, MT, Brasil & S $8^{\circ} 46^{\prime} 45.11^{\prime \prime}, \mathrm{O} 57^{\circ} 27^{\prime} 55.44^{\prime \prime}$ & Potamotrygon sp_tpj1 & Dezembro, 2005 \\
\hline & & & & Potamotrygon sp_tpj2 & \\
\hline \multirow[t]{5}{*}{ Purus } & Rio Tarauacá, Lago Arara & Tarauacá, AC, Brasil & S $8^{\circ} 4^{\prime} 5.88^{\prime \prime}, \mathrm{O} 70^{\circ} 43^{\prime} 4.80^{\prime \prime}$ & Paratrygon aiereba & Julho, 2006 \\
\hline & & & & Potamotrygon orbignyi & \\
\hline & & & & Potamotrygon sp_tar1 & \\
\hline & & & & Potamotrygon sp_tar2 & \\
\hline & Rio Purus, Lago Novo & Boca do Acre, AM, Brasil & S $8^{\circ} 44^{\prime} 45.6^{\prime \prime}, \mathrm{O} 67^{\circ} 22^{\prime} 51.6^{\prime \prime}$ & Potamotrygon motoro & Julho, 2006 \\
\hline \multirow[t]{5}{*}{ Madeira } & Rio Madeira, Rio Jamari, Represa Samuel & Itapoã do Oeste, RR, Brasil & S 9 4' 33.96", O 63 18' 17.64" & Potamotrygon sp_jam & Julho, 2006 \\
\hline & Rio Abacaxis & Borba, AM, Brasil & S $4^{\circ} 16^{\prime} 58.07 "$, O $58^{\circ} 36^{\prime} 42.48^{\prime \prime}$ & Potamotrygon cf. motoro & Janeiro, 2007 \\
\hline & & & S 4 16' 8.4", O 58³9' 13.32" & Potamotrygon humerosa & \\
\hline & & & S $4^{\circ} 24^{\prime} 34.2^{\prime \prime}$, O $58^{\circ} 39^{\prime} 43.91^{\prime \prime}$ & & \\
\hline & Rio Madre de Dios & Boca Manu, Fitzcarralda, Peru & $\mathrm{S} 12^{\circ} 17^{\prime} 47^{\prime \prime}, \mathrm{O} 70^{\circ} 54^{\prime} 26^{\prime \prime}$ & Potamotrygon tatianae & Maio, 2001 \\
\hline \multirow[t]{12}{*}{ Negro/Branco } & Rio Negro & Barcelos, AM, Brasil & $\mathrm{S} 0^{\circ} 98^{\prime}, \mathrm{O} 62^{\circ} 92^{\prime}$ & Paratrygon aiereba & Outubro, 1996 \\
\hline & & & S $0^{\circ} 46^{\prime} 31.8^{\prime \prime}$, O $62^{\circ} 56^{\prime} 14.28^{\prime \prime}$ & Potamotrygon orbignyi & Fevereiro, 2004 \\
\hline & & & $\mathrm{S} 0^{\circ} 45^{\prime} 29.87^{\prime \prime}, \mathrm{O} 62^{\circ} 59^{\prime} 18.23^{\prime \prime}$ & Potamotrygon motoro & Março, 2004 \\
\hline & & & S $0^{\circ} 58^{\prime} 38.64^{\prime \prime}, \mathrm{O} 62^{\circ} 54^{\prime} 46.44^{\prime \prime}$ & Potamotrygon schroederi & \\
\hline & & & $\mathrm{S} 0^{\circ} 52^{\prime} 11.28^{\prime \prime}, \mathrm{O} 62^{\circ} 46^{\prime} 37.92^{\prime \prime}$ & Potamotrygon sp (cururu) & \\
\hline & & & S $0^{\circ} 54^{\prime} 24.11 "$, O $62^{\circ} 58^{\prime} 21.72^{\prime \prime}$ & Potamotrygon sp & \\
\hline & & & $\mathrm{S} 0^{\circ} 40^{\prime} 23.16^{\prime \prime}, \mathrm{O} 63^{\circ} 12^{\prime} 7.56^{\prime \prime}$ & & \\
\hline & & & S $0^{\circ} 46^{\prime} 41.88^{\prime \prime}, \mathrm{O} 63^{\circ} 8^{\prime} 10.32^{\prime \prime}$ & & \\
\hline & Rio Branco, Rio Urariquera & Boa Vista, RR, Brasil & N 322' 51.95", O $60^{\circ} 35^{\prime} 44.15^{\prime \prime}$ & Paratrygon aiereba & Fevereiro, 2007 \\
\hline & & & & Potamotrygon sp & \\
\hline & & & & Potamotrygon scobina & \\
\hline & & & & Potamotrygon orbignyi & \\
\hline
\end{tabular}




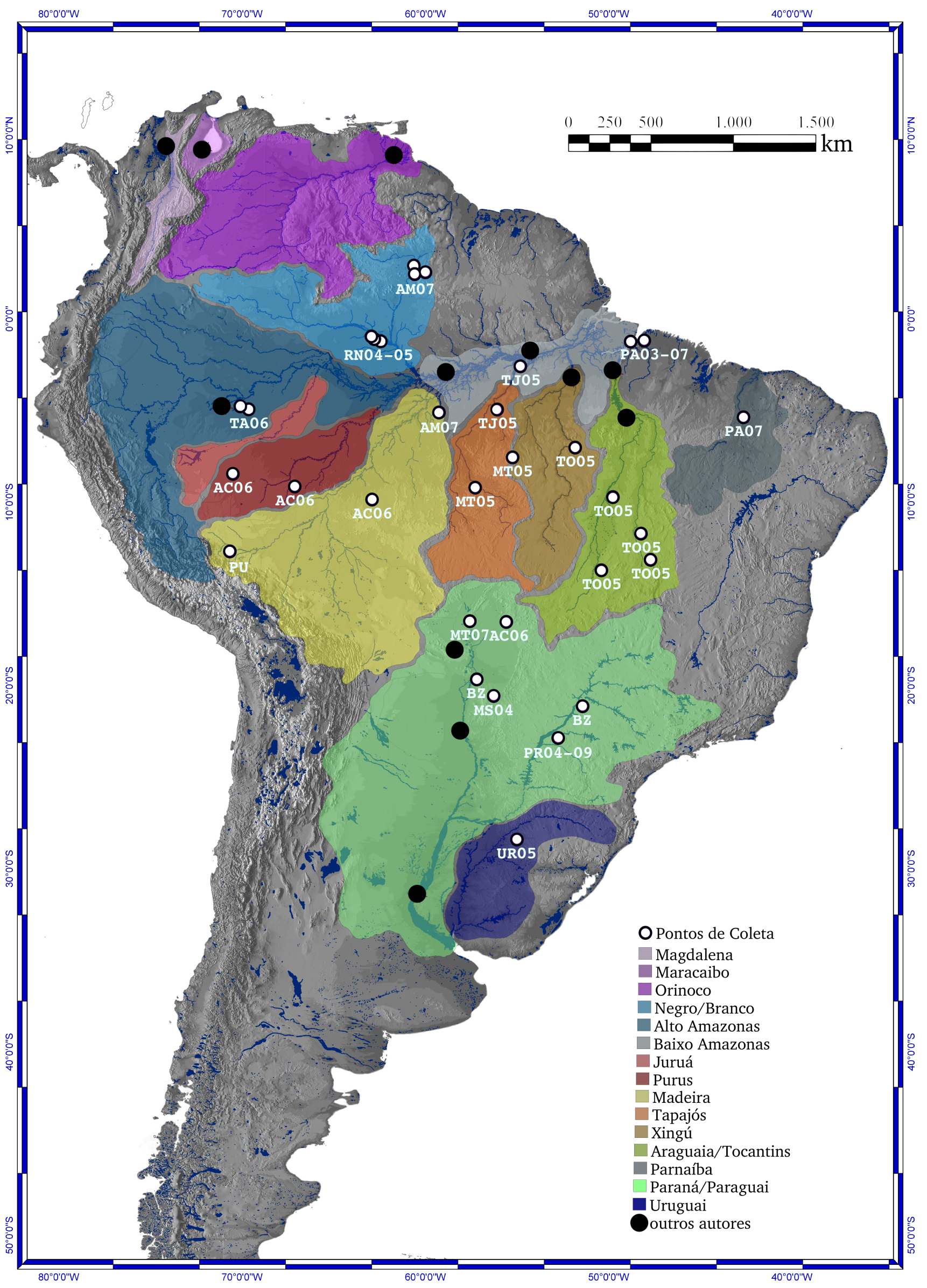

Figura 2. Localidades de coleta dos hospedeiros amostrados neste estudo. Os códigos plotados servem de referência para a obtenção das localidades amostradas no banco de dados eletrônico disponível em http://www.ib.usp.br/hpc/hpc_search.php (Marques \& Domingues, 2006). 


\section{Material tipo, vouchers e espécimes adicionais}

Espécimes de Potamotrygonocestus depositados em coleções helmintológicas foram analisados no presente estudo (Tabela 2), sendo material tipo e vouchers emprestados pelas seguintes instituições: USNPC: United States National Parasite Collection, Beltsville, Maryland, Estados Unidos; CHIOC: Coleção Helmintológica do Instituto Oswaldo Cruz, Rio de Janeiro, Brasil; MZUSP: Museu de Zoologia da Universidade de São Paulo, São Paulo, Brasil. Os holótipos de $P$. magdalenensis, $P$. amazonensis e $P$. orinocoensis não foram emprestados pela USNPC e foram analisados através de fotografias obtidas por F.P.L.M. em visita à coleção.

Tabela 2. Espécimes de Potamotrygonocestus analisados neste estudo procedentes de coleções de referência.

\begin{tabular}{|c|c|c|c|c|c|}
\hline $\mathrm{N}^{0}$ de tombo & Espécie & Localidade & Hospedeiro & Categoria & Referên cia \\
\hline USNPC 73542 & P. magdalenensis & Cienaga Rabón, San Cristóbal, Bolívar, Colômbia & P. magdalenae & holótipo & Brooks \& Thorson, 1976 \\
\hline USNPC 73543a & P. magdalenensis & Cienaga Rabón, San Cristóbal, Bolívar, Colômbia & P. magdalenae & parátipo & Brooks \& Thorson, 1976 \\
\hline USNPC $73543 b$ & P. magdalenensis & Cienaga Rabón, San Cristóbal, Bolívar, Colômbia & P. magdalenae & parátipo & Brooks \& Thorson, 1976 \\
\hline USNPC 76363 & P. amazonensis & Rio Itacuaí, Atalaia do Norte, AM, Brasil & P. orbignyi & holótipo & Mayes et al., 1981 \\
\hline USNPC 75713 & P. orinocoensis & Delta do rio Orinoco, El Toro, Venezuela & P. orbignyi & holótipo & Brooks et al., 1981 \\
\hline USNPC 75714a & P. orinocoensis & Delta do rio Orinoco, El Toro, Venezuela & P. orbignyi & parátipo & Brooks et al., 1981 \\
\hline USNPC 75714b & P. orinocoensis & Delta do rio Orinoco, El Toro, Venezuela & P. orbignyi & parátipo & Brooks et al., 1981 \\
\hline CHIOC $31847 \mathrm{a}$ & P. travassossi & Rio Amazonas, Maicuru, Monte Alegre, PA, Brasil & P. orbignyi & holótipo & Rego, 1979 \\
\hline CHIOC $31847 \mathrm{e}$ & P. travassossi & Rio Amazonas, Maicuru, Monte Alegre, PA, Brasil & P. orbignyi & parátipo & Rego, 1979 \\
\hline CHIOC $32816 \mathrm{a}$ & P. orinocoensis & Corumbá, MT, Brasil & P. motoro & voucher & Brooks \& Amato, 1992 \\
\hline CHIOC $32816 b$ & P. orinocoensis & Corumbá, MT, Brasil & P. motoro & voucher & Brooks \& Amato, 1992 \\
\hline CHIOC $32816 \mathrm{c}$ & P. orinocoensis & Corumbá, MT, Brasil & P. motoro & voucher & Brooks \& Amato, 1992 \\
\hline CHIOC $32816 \mathrm{e}$ & P. orinocoensis & Corumbá, MT, Brasil & P. motoro & voucher & Brooks \& Amato, 1992 \\
\hline CHIOC $32816 \mathrm{f}$ & P. orinocoensis & Corumbá, MT, Brasil & P. motoro & voucher & Brooks \& Amato, 1992 \\
\hline CHIOC 36976 & P. travassossi & Rio Paraná, Porto Rico, PR, Brasil & P. falkneri & voucher & Lacerda et al., 2008 \\
\hline MZUSP 5837 & P. chaoi & Paraná Janauacá e rio Solimões, Manaus, AM, Brasil & P. iwamae & holótipo & Marques et al., 2003 \\
\hline MZUSP 5838 & P. chaoi & Paraná Janauacá e rio Solimões, Manaus, AM, Brasil & P. iwamae & parátipo & Marques et al., 2003 \\
\hline MZUSP 5840 & P. chaoi & Paraná Janauacá e rio Solimões, Manaus, AM, Brasil & P. iwamae & parátipo & Marques et al., 2003 \\
\hline MZUSP 5841 & P. chaoi & Paraná Janauacá e rio Solimões, Manaus, AM, Brasil & P. iwamae & parátipo & Marques et al., 2003 \\
\hline MZUSP 5845 & P. fitzgeraldae & Rio Negro, Barcelos, AM, Brasil & P. aiereba & holótipo & Marques et al., 2003 \\
\hline MZUSP 5846 & P. fitzgeraldae & Rio Negro, Barcelos, AM, Brasil & P. aiereba & parátipo & Marques et al., 2003 \\
\hline MZUSP 5847 & P. fitzgeraldae & Rio Negro, Barcelos, AM, Brasil & P. aiereba & parátipo & Marques et al., 2003 \\
\hline MZUSP 5848 & P. fitzgeraldae & Rio Negro, Barcelos, AM, Brasil & P. aiereba & parátipo & Marques et al., 2003 \\
\hline MZUSP 5849 & P. fitzgeraldae & Rio Negro, Barcelos, AM, Brasil & P. aiereba & parátipo & Marques et al., 2003 \\
\hline MZUSP 5850 & P. fitzgeraldae & Rio Negro, Barcelos, AM, Brasil & P. aiereba & parátipo & Marques et al., 2003 \\
\hline MZUSP 5851 & P. fitzgeraldae & Rio Negro, Barcelos, AM, Brasil & P. aiereba & parátipo & Marques et al., 2003 \\
\hline MZUSP 5852 & P. fitzgeraldae & Rio Negro, Barcelos, AM, Brasil & P. aiereba & parátipo & Marques et al., 2003 \\
\hline MZUSP 5853 & P. fitzgeraldae & Rio Negro, Barcelos, AM, Brasil & P. aiereba & parátipo & Marques et al., 2003 \\
\hline MZUSP 5854 & P. maurae & Rio Negro, Barcelos, AM, Brasil & P. orbignyi & holótipo & Marques et al., 2003 \\
\hline MZUSP 5855 & P. maurae & Rio Negro, Barcelos, AM, Brasil & P. orbignyi & parátipo & Marques et al., 2003 \\
\hline MZUSP 5856 & P. maurae & Rio Negro, Barcelos, AM, Brasil & P. orbignyi & parátipo & Marques et al., 2003 \\
\hline MZUSP 5857 & P. maurae & Rio Negro, Barcelos, AM, Brasil & P. orbignyi & parátipo & Marques et al., 2003 \\
\hline MZUSP 5858 & P. sp 7 & Rio Tocantins, Marabá, PA, Brasil & P. henlei & voucher & Marques et al., 2003 \\
\hline MZUSP 5859 & P. sp 8 & Rio Negro e rio Solimões, Manaus, AM, Brasil & P. schroederi & voucher & Marques et al., 2003 \\
\hline MZUSP 5860 & $P . \operatorname{sp} 8$ & Rio Negro e rio Solimões, Manaus, AM, Brasil & P. schroederi & voucher & Marques et al., 2003 \\
\hline MZUSP 5861 & P. sp 8 & Rio Negro e rio Solimões, Manaus, AM, Brasil & P. schroederi & voucher & Marques et al., 2003 \\
\hline MZUSP 5862 & $P . \operatorname{sp} 8$ & Rio Negro e rio Solimões, Manaus, AM, Brasil & P. schroederi & voucher & Marques et al., 2003 \\
\hline MZUSP 5863 & P. sp 8 & Rio Negro e rio Solimões, Manaus, AM, Brasil & P. schroederi & voucher & Marques et al., 2003 \\
\hline MZUSP 5864 & P. sp 8 & Rio Negro e rio Solimões, Manaus, AM, Brasil & P. schroederi & voucher & Marques et al., 2003 \\
\hline
\end{tabular}


Além do material depositado em coleções de referência, também foram analisados dois espécimes de P. magdalenensis coletados na localidade tipo pertencentes à coleção pessoal de D.R. Brooks e onze espécimes de P. magdalenensis coletados em Ciénaga Grande, Estación Piscícola Repelón, Colômbia, pertencentes à coleção pessoal de J.Caira (ver Caira \& Orringer, 1995).

\section{Obtenção de dados em microscopia óptica}

Os espécimes de Potamotrygonocestus coletados foram hidratados em séries alcoólicas regressivas, corados com Hematoxilina de Mayer ou de Delafield, desidratados em séries alcoólicas progressivas, diafanizados em Salicilato de Metila e montados em lâmina e lamínula com Bálsamo do Canadá.

Dados merísticos e morfométricos foram obtidos em um microscópio óptico Olympus BX51 com ocular micrométrica. Dados morfométricos dos ganchos foram medidos através de imagens obtidas pelo software analySIS 5.0 Olympus Soft Images Solutions por uma câmera Olympus SC30 acoplada em um microscópio óptico Olympus BX51. As imagens dos ganchos e dos holótipos depositados na USNPC foram analisadas com o programa UTHSCSA Image Tool ver. 3.00 (Wilcox et al., 2002).

Os parâmetros morfométricos e merísticos considerados neste estudo seguem aqueles tradicionalmente utilizados na taxonomia do gênero (Tabela 3). Para a análise dos ganchos foram designados quatro novos parâmetros merísticos além dos tradicionais (Tabela 3; Figura 3). As medidas de proglótides não destacadas foram obtidas na proglótide imatura mais distal no estróbilo, em todas as proglótides maduras quando presentes e em todas as proglótides grávidas quando presentes.

Parâmetros morfométricos estão expressos em micrômetros, exceto se indicado outra unidade métrica. Todos os parâmetros são apresentados nesta ordem: variação, média, desvio padrão e número amostral. No caso de medidas bidimensionais, o comprimento é apresentado antes da largura. As medidas do ovário são expressas nesta ordem: largura do istmo, comprimento do lobo poral e comprimento do lobo aporal. Os parâmetros que não foram observados devido ao táxon não apresentar determinado estágio de maturidade foram classificados como não aplicáveis. Os parâmetros que não foram observados devido à indisponibilidade de determinado estágio de maturidade foram classificados como indisponíveis.

\section{Obtenção de dados em microscopia eletrônica de varredura}

Espécimes adultos e proglótides destacadas com o cirro evertido foram selecionados para microscopia eletrônica de varredura (M.E.V.). Os espécimes adultos selecionados tiveram seus 
Tabela 3. Parâmetros morfométricos e merísticos analisados em espécimes de Potamotrygonocestus neste estudo.

\section{Parâmetro}

Comprimento do estróbilo

Número de proglótides

Comprimento do escólex

Largura do escólex

Comprimento do botrídeo

Largura do botrídeo

Comprimento da ventosa apical

Largura da ventosa apical

Comprimento total do gancho

Comprimento da base do gancho

*Comprimento da furca do gancho

* Largura do gancho na furca

* Largura da base da furca

*Inserção da furca na base do gancho

Comprimento do segmento imaturo

Largura do segmento imaturo

Comprimento do segmento maduro

Largura do segmento maduro

Comprimento do segmento grávido

Largura do segmento grávido

Comprimento do segmento pós grávido

Largura do segmento pós grávido

Número total de testículos

Número de testículos porais

Número de testículos aporai

Comprimento dos testículos

Largura dos testículos

Posição do poro genital

Largura do istmo do ovário

Comprimento do lobo poral do ovário

Comprimento do lobo aporal do ovário

*Parâmetros designados a partir deste estudo

\section{Descriçãa}

Distância no sentido ântero-posterior entre o início da região de crescimento e a extremidade distal da última proglótide presa ao estróbilo.

Contagem dos segmentos com margens anterior e posterior distinguíveis a partir da região de crescimento. Inclui todos os estágios de maturação

Distância no sentido ântero-posterior entre a extremidade proximal da ventosa apical e a extremidade distal do botrídeo.

Distância na região de maior largura do escólex entre as margens laterais dos botrídeos.

Distância no sentido ântero-posterior entre as extremidades proximal e distal do botrídeo

Distância na região de maior largura entre as margens laterais do botrídeo.

Distância no sentido ântero-posterior entre as extremidades proximal e distal da ventosa apical.

Distância na região de maior largura entre as margens laterais da ventosa apical.

Distância no sentido ântero-posterior entre a extremidade proximal da base do gancho e a porção mais distal da furca do gancho (Fig.3 A-B).

Distância no sentido ântero-posterior entre a extremidade proximal e distal da base do gancho (Fig.3 A-C)

Distância seguindo a curvatura da furca, entre as extremidades proximal e distal da furca do gancho (Fig.3 D-E)

Distância na região de maior largura na altura da furca entre a margem lateral da furca e a margem lateral da base do gancho (Fig.3 F-G).

Distância na região de inserção da furca na base do gancho (Fig.3 H-I).

Distância entre a extremidade proximal da base do gancho e extremidade proximal da base da furca (Fig.3 A-J)

Distância no sentido ântero-posterior entre as extremidades proximal e distal da proglótide imatura mais distal do estróbilo ou destacada.

Distância na região mais larga entre margens laterais da proglótide imatura mais distal do estróbilo ou destacada.

Distância no sentido ântero-posterior entre as extremidades proximal e distal de todas as proglótides maduras do estróbilo ou proglótide madura destacada.

Distância na região mais larga entre margens laterais de todas as proglótides maduras do estróbilo ou proglótide madura destacada.

Distância no sentido ântero-posterior entre as extremidades proximal e distal de todas as proglótides grávidas do estróbilo ou proglótide grávida destacada.

Distância na região mais larga entre margens laterais de todas as proglótides grávidas do estróbilo ou proglótide grávida destacada.

Distância no sentido ântero-posterior entre as extremidades proximal e distal de proglótide pós grávida destacada.

Distância na região mais larga entre margens laterais de proglótide pós grávida destacada.

Contagem de todos os testículos de proglótide destacada ou da proglótide mais distal, todas as maduras e todas as grávidas do estróbilo.

Contagem de todos os testículos porais de proglótide destacada ou da proglótide mais distal, todas as maduras e todas as grávidas do estróbilo.

Contagem de todos os testículos aporais de proglótide destacada ou da proglótide mais distal, todas as maduras e todas as grávidas do estróbilo.

Distância entre as extremidades proximal e distal dos cinco testículos mais posteriores de cada proglótide destacada ou da proglótide mais distal, todas as maduras e todas as grávidas do estróbilo.

Distância entre as margens laterais dos cinco testículos mais posteriores de cada proglótide destacada ou da proglótide mais distal, todas as maduras e todas as grávidas do estróbilo.

Distância entre o poro genital e a extremidade distal da proglótide. Representada em \% a partir da extremidade distal.

Distância entre as margens laterais do istmo do ovário de cada proglótide destacada ou da proglótide mais distal, todas as maduras e todas as grávidas do estróbilo.

Distância entre extremidades anterior e posterior do lobo poral do ovário de cada proglótide destacada ou da proglótide mais distal, todas as maduras e todas as grávidas do estróbilo.

Distância entre extremidades anterior e posterior do lobo poral do ovário de cada proglótide destacada ou da proglótide mais distal, todas as maduras e todas as grávidas do estróbilo. 

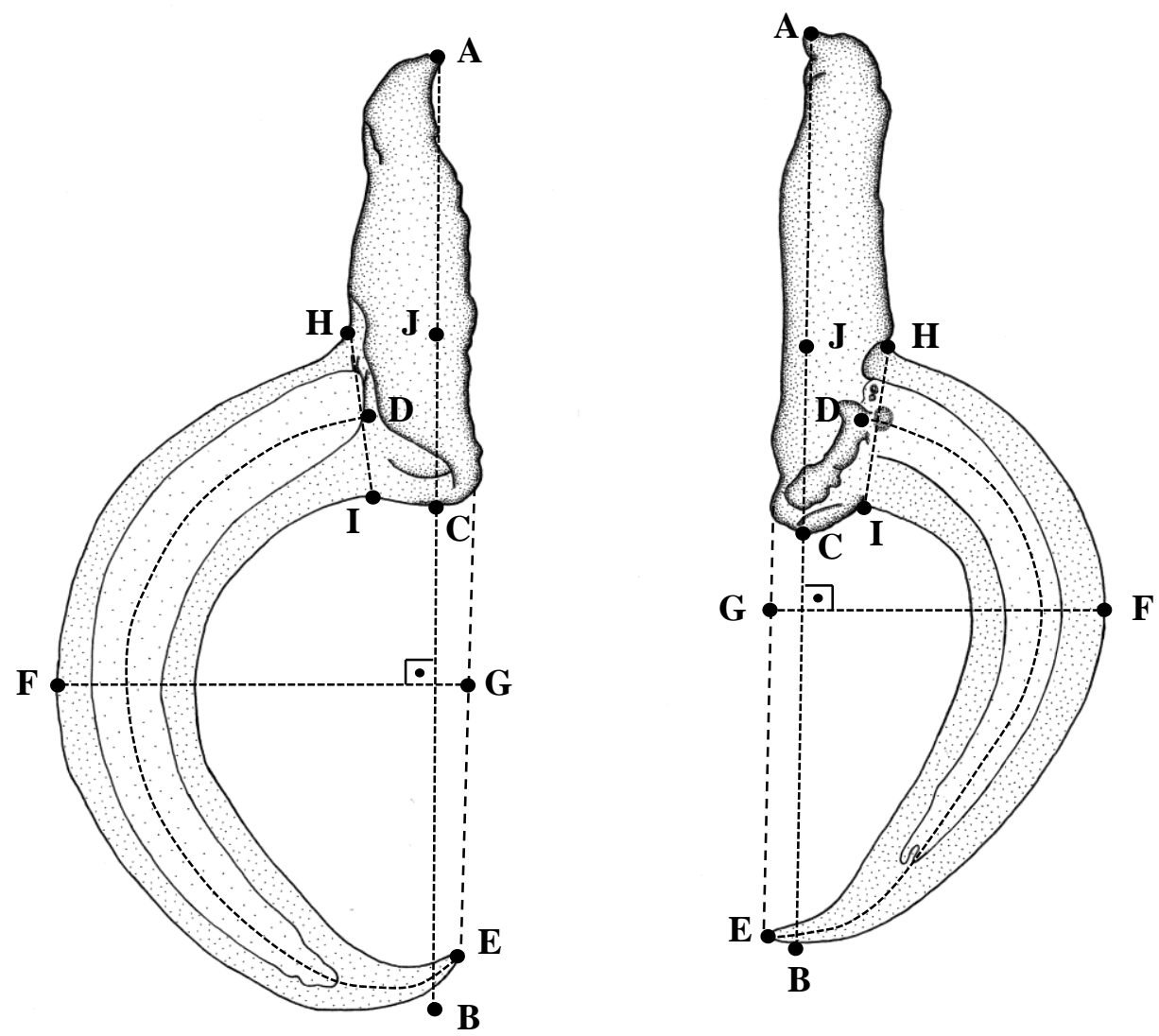

Figura 3. Marcos e trajetória linear para a obtenção de dados morfométricos para os ganchos analisados nos ganchos de Potamotrygonocestus neste estudo. A descrição de cada parâmetro está detalhada na Tabela 4.
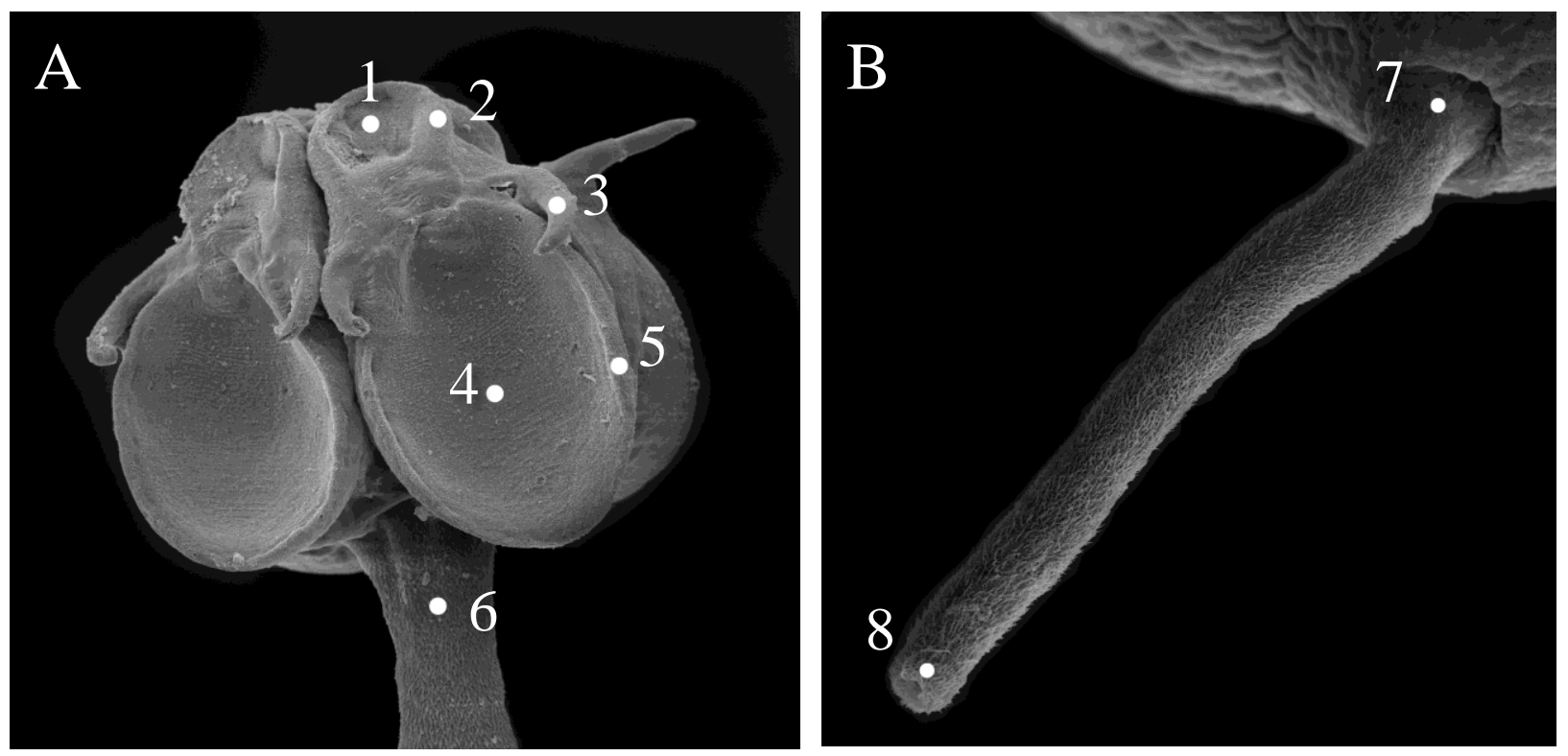

Figura 4. Regiões de captura de micrografias eletrônicas para Potamotrygonocestus. 1: superfície proximal da ventosa apical; 2: superfície distal da ventosa apical; 3: superfície da epiderme que recobre o gancho; 4: superfície proximal do botrídeo; 5: superfície distal do botrídeo; 6: superfície da região de crescimento; 7: superfície da porção proximal do cirro, e 8: superfície da região distal do cirro. 
escóleces separados de seus estróbilos e seus estróbilos foram montados em lâminas permanentes para posterior identificação seguindo o protocolo para preparação de espécimes para microscopia óptica. Os escóleces e proglótides com cirro evertido foram hidratados em séries alcoólicas regressivas, imersos em solução de Tetróxido de Ósmio 1\% por aproximadamente 1 hora, desidratados em séries alcoólicas progressivas, imersos em hexametildisalazano, secos ao ar livre por aproximadamente 12 horas, montados em suportes de alumínio e cobertos com ouro no metalizador Bal-Tec SCD050 Balzers Sputter Coater. Os espécimes foram analisados sob microscópio eletrônico de varredura Zeiss DSM-940 no Laboratório de Biologia Celular e Microscopia Eletrônica e Confocal do Instituto de Biociências (IB-USP). As regiões de captura das imagens seguem Luchetti et al.(2008) (Figura 4).

As micrografias obtidas foram analisadas com o programa UTHSCSA Image Tool ver. 3.00 (Wilcox et al., 2002). As imagens foram divididas em quadrantes de $1 \mu \mathrm{m}^{2}$ para obtenção da densidade de microtríquias. Para cada imagem foram selecionados 10 quadrantes aleatórios nos quais foi efetuada a contagem de microtríquias. Para a obtenção de dados morfométricos, foram selecionadas até 10 microtríquias de cada tipo para cada região observada.

Parâmetros morfométricos estão expressos em micrômetros e todos os parâmetros são apresentados nesta ordem: variação, média, desvio padrão e número amostral. No caso de medidas bidimensionais, o comprimento é apresentado antes da largura, que para microtríquias é a medida da largura da base. Os parâmetros que não foram observados devido ao táxon não apresentar determinada morfologia das microtríquias foram classificados como não aplicáveis. Os parâmetros que não foram observados devido à indisponibilidade de imagens de determinada região de captura foram classificados como indisponíveis. A nomenclatura empregada na descrição das microtríquias segue Chervy (2009).

\section{Depósito em coleção de referência}

Os espécimes analisados para obtenção de dados merísticos e morfométricos foram depositados na Coleção de Helmintologia do Museu de Zoologia da Universidade de São Paulo (MZUSP). Os números de tombamento e descrições de cada lote são apresentados após a descrição de cada espécie. As abreviações utilizadas são: adult.: adulto; progl.: proglótide; imat.: imaturo (a); mad.: maduro (a); gráv.: gravido (a); pgrav.: pós grávida; incomp.: incompleto (a).

\section{RESULTADOS E DISCUSSÃO}

\section{Processamento do material biológico e obtenção de helmintos}

A triagem das 1060 válvulas espirais amostradas para este estudo resultou em 976 
infectadas por espécimes do gênero Potamotrygonocestus. Dos cerca de 3000 espécimes de Potamotrygonocestus encontrados, 1753 foram analisadas para obtenção de dados merísticos e morfométricos. Cerca de 50 preparações foram feitas para análise em M.E.V.. Os dados morfométricos obtidos em microscopia óptica estão dispostos no Anexo I e os dados provenientes de M.E.V. estão no Anexo II. Com base nestes dados, as decisões taxonômicas adotadas foram:

\section{Descrições taxonômicas}

Potamotrygonocestus magdalenensis Brooks \& Thorson, 1976

(Figura 5 A-D)

Potamotrygonocestus magdalenensis Brooks \& Thorson, 1976: 943-946, Figura 1-4 (descr., Holótipo USNPC 73542, examinado); Brooks, Mayes \& Thorson, 1981: 48, Figura 5 (diagnose e filogenia); Caira \& Orringer, 1995: 23 (morfologia); Brooks, 1992: 589 (distribuição e biogeografia); Brooks \& Amato 1992: 397 (especificidade); Marques, Brooks \& Araújo, 2003: 369-371, Figura 1 (redescr.).

Redescrição: [baseada em 10 espécimes adultos completos, 2 espécimes adultos incompletos e 4 proglótides destacadas; dados de M.E.V. retirados de Caira \& Orringer (1995)] Estróbilo acraspédoto, hiperapolítico (Figura 5A); espécimes completos 0,45-2,25 (1,13 $\pm 0,66, \mathrm{n}=9) \mathrm{mm}$ de comprimento, compostos de 7-13 $(10 \pm 2, \mathrm{n}=6)$ proglótides. Escólex 195,75-297,54 (235,25 \pm $33,55, \mathrm{n}=11) \times 180,09-376,90(258,2 \pm 59, \mathrm{n}=11)$ (Figura 5B), formada por quatro botrídeos não septados, cada um com uma ventosa apical e um par de ganchos simples. Botrídeo 186,20-277,40 $(218,66 \pm 32,18, \mathrm{n}=10) \times 87,40-144,40(117,22 \pm 19,25, \mathrm{n}=10)$, coberto proximalmente por espinitríquias gladiadas, cerca de $2-3 \mu \mathrm{m}$ de comprimento e distalmente por espinitríquias gladiadas, cerca de $1 \mu \mathrm{m}$ de comprimento. Ventosa apical 15,20-48,10 $(22,75 \pm 9,08, \mathrm{n}=11) \times 24,2-$ 48,10 (29,65 $\pm 6,51, \mathrm{n}=11)$. Ganchos assimétricos (Figura 5C), gancho lateral 0,72-1,01 (0,91 \pm $0,16, n=3$ ) do comprimento do gancho medial; furca emergindo lateralmente da região central da base. Gancho lateral 35,44-72,25 $(53,63 \pm 15,35, \mathrm{n}=4)$ de comprimento, base 20,36-28,92 (23,65 \pm $3,68, \mathrm{n}=4)$, furca $56,96-83,27(66,16 \pm 11,81, \mathrm{n}=4)$, largura na furca $26,63-36,38(30,43 \pm 4,25$, $\mathrm{n}=4)$, base da furca 8,09-14,16 (10,28 $\pm 2,75, \mathrm{n}=4)$, inserção da furca a partir de $25-34 \%(31 \pm 4$, $\mathrm{n}=4)$ da base do gancho. Gancho medial 36,38-56,94 (46,59 $\pm 6,53, \mathrm{n}=7)$ de comprimento, base 14,63-24,89 (19,97 $\pm 4,77, n=7)$, furca 48,18-62,42 (54,09 $\pm 5,03, n=7)$, largura na furca 21,31$28,30(24,47 \pm 2,64, n=7)$, base da furca 3,34-11 $(6,47 \pm 2,86, n=7)$, inserção da furca a partir de 23$44 \%(31 \pm 8, \mathrm{n}=7)$ da base do gancho. Região de crescimento coberta por espinitríquias gladiadas, cerca de $8 \mu \mathrm{m}$ de comprimento, distribuídas entre filitríquias aciculares.

Proglótide imatura 518,30 x 271,40 (n=1); proglótide madura destacada (Figura 5D) 681,21$1628,64(1181,65 \pm 475,97, n=3) \times 301,60-501,12(387,63 \pm 102,55, n=3)$; proglótide grávida 


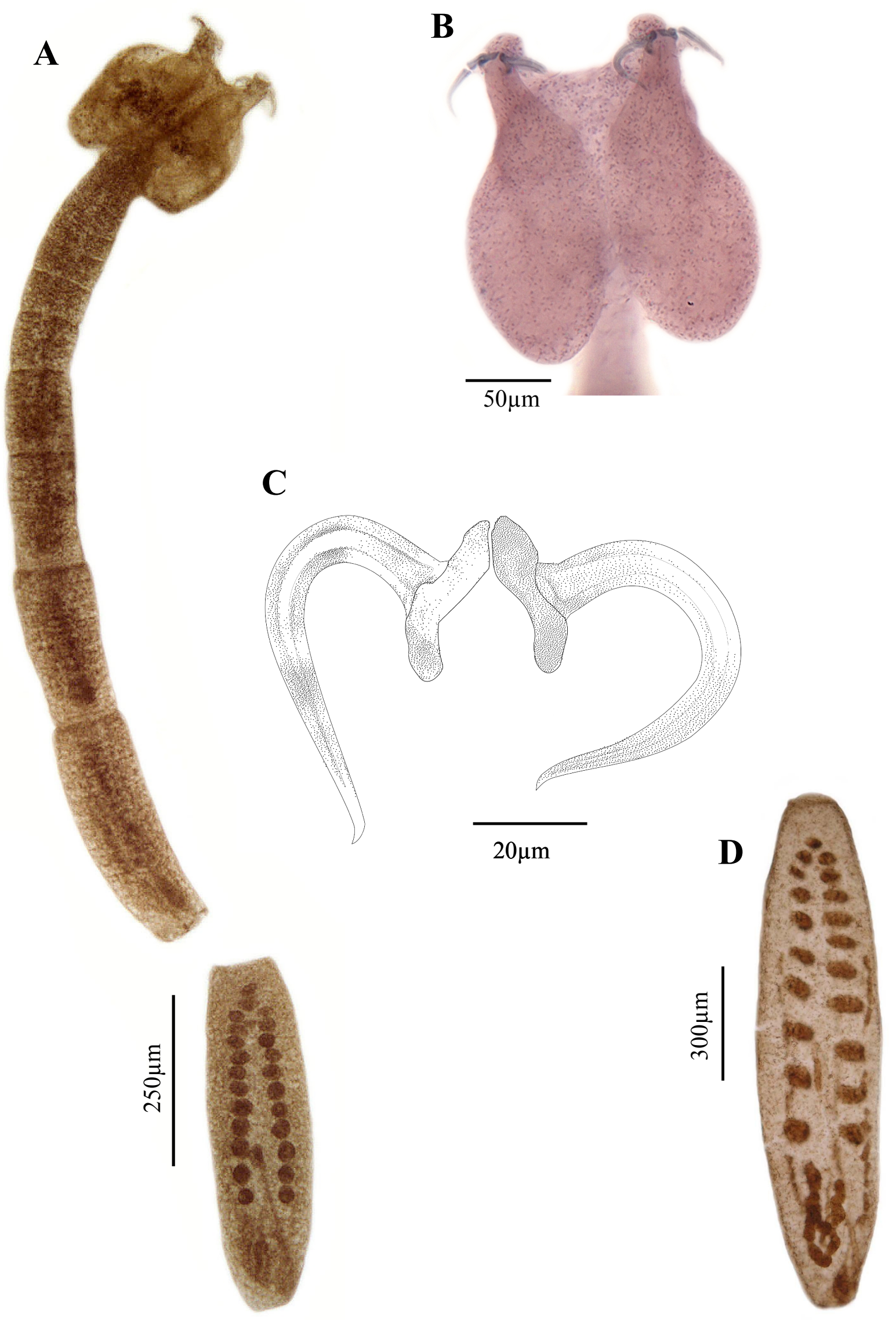

Figura 5. Potamotrygonocestus magdalenensis. A: espécime completo (holótipo USNM Helm.Coll.73542). B: ganchos (MZUSP6973). C: escólex (MZUSP6972). D: proglótide madura (parátipoUSNMHel.Coll.73543). 
destacada 1934,01 x 438,48 (n=1). Testículos em duas colunas longitudinais anteriores ao ovário; testículos $28(\mathrm{n}=1)$ em número, 14 poralmente e 14 aporalmente; proglótide madura destacada 80,52-102,48 $(91,01 \pm 6,09, \mathrm{n}=10) \times 78,08-97,60(88,82 \pm 6,32, \mathrm{n}=10)$. Poro genital postero-lateral, posterior ao término do ovário (Figura 5D), átrio genital ausente; 2,88-4,6\% $(n=2)$ da margem posterior da proglótide madura destacada; $0,81 \%(\mathrm{n}=1)$ da margem posterior da proglótide grávida . Cirro coberto com espinitríquias rostradas, mais dispersas proximalmente, cerca de $2-3 \mu \mathrm{m}$ de comprimento. Vitelária em duas colunas laterais aos testículos, estendendo-se até o início do ovário, nunca ultrapassando o istmo ovariano. Ovário na porção terminal da proglótide, em forma de A invertido, assimétrico; proglótide madura destacada 72,89 $(n=1), 215,63(n=1), 258,65(n=1)$.

Hospedeiro tipo: Potamotrygon magdalenae (Valenciennes, 1865)

Localidade tipo: Ciénaga Rabón, província de San Cristóbal, Bolívar, Colômbia.

Localidade adicional: Ciénaga Grande, Estación Piscícola Repelón, Colômbia.

Material examinado: USNM Helm. Coll. 73542 (holótipo): 1 adult. imat.; USNM Hel. Coll. 73543 a,b (parátipos): 1 adult. imat., 1 progl. mad.; MZUSP 6971: 7 adult. imat., em Potamotrygon magdalenae (C-15), Ciénaga Grande, Estación Piscícola Repelón, Colômbia; col. J. Caira. MZUSP 6972: 1 adult. imat., 2 progl. mad., 1 progl. grav., em P. magdalenae (C-13), Ciénaga Grande, Estación Piscícola Repelón, Colômbia; col. J. Caira. MZUSP 6973: 1 adult. imat., em P. magdalenae (D. R. Brooks pers. col.), Ciénaga Rabón, província de San Cristóbal, Bolívar, Colômbia [?]; col. D. R. Brooks.

\section{Considerações taxonômicas:}

Espécie tipo do gênero, P. magdalenensis foi descrita por Brooks \& Thorson (1976) baseada somente em dados morfométricos de 9 espécimes adultos completos e 12 proglótides destacadas. Dando ênfase à morfologia dos ganchos e a posição destes no botrídeo, os autores creditaram as diferenças entre esta espécie e outros oncobotrí́deos marinhos à físiologia dos hospedeiros, adaptados à água doce. Posteriormente, Caira \& Orringer (1995) complementaram a descrição da espécie com dados de M.E.V. e histológicos, inéditos para o gênero, porém não acrescentaram dados morfométricos à descrição. Dos 20 espécimes coletados por J. Caira em Ciénaga Grande, Colômbia, metade foi destinada para preparações histológicas completas, porém apenas 1 destes foi depositado em coleções de referência (H.W. Manter Lab., Universidade de Nebraska, EUA, $n^{\circ}$ 37546, não disponível para este estudo). Os espécimes coletados e que não foram analisados morfometricamente para a complementação da descrição (coleção pessoal de J. Caira, ver Caira \& Orringer, 1995) foram analisados agora, mostrando-se menores que aqueles usados na descrição original $(0,45-1,42$ vs. 1,15-2,25).

$\mathrm{Na}$ última revisão feita para o gênero, Marques et al. (2003) redescreveram a espécie baseados na série tipo, dois espécimes pertencentes à coleção pessoal de D. R. Brooks (também analisados no presente estudo) e um indivíduo depositado no H.W. Manter Lab. no 37546 . Com mais espécimes disponíveis, os autores aumentaram a amplitude dos atributos morfométricos desta 
espécie, e consideraram que os comprimentos do botrídeo e dos ganchos lateral e medial e a ausência de átrio genital seriam úteis para diagnosticar P. magdalenensis. De acordo com os dados apresentados aqui, P. magdalenensis possui botrídio com 186-277 e ganchos lateral e medial com 35-72 e 36-56 de comprimento, respectivamente. No entanto, estes valores se sobrepõem com aqueles obtidos para outras espécies (ver descrições adiante), indicando que estes caracteres não permitem a diagnose da espécie. A ausência do átrio genital também é observada em outras espécies de Potamotrygonocestus (ver descrições adiante), não sendo considerado informativo.

Entre os parâmetros morfométricos avaliados para P. magdalenensis, todos apresentaram sobreposição com as demais espécies do gênero, exceto em alguns casos quando comparados com P. chaoi (e.g. comprimento do estróbilo, Anexo I). Esta observação também é verdade para caracteres considerados mais robustos, por não estarem sujeitos à artefatos de fixação (e.g. número de proglótides e de testículos, Anexo I). Dentre todos os parâmetros morfológicos avaliados, a morfologia do gancho mostrou-se como única capaz de ser utilizada na diagnose de $P$. magdalenensis. Os ganchos de P. magdalenensis são assimétricos, sendo o gancho lateral arredondado e com a extremidade distal voltada para o lado, enquanto o gancho medial possui uma angulação na altura da inserção da furca na base, com a extremidade distal voltada para baixo (Figura 5C).

A indisponibilidade de espécimes para novas observações sob M.E.V. impediu que caracteres relacionados à morfologia das microtríquias pudessem ser avaliados para $P$. magdalenensis. Os dados disponíveis por Caira \& Orringer (1995) não permitem sejam feitas comparações que possam levar à diagnose da espécie, pois não apresentam dados de densidade, comprimento e largura de microtríquias para todas as regiões do escólex e do cirro analisadas neste estudo (Anexo II). É necessário, portanto, que novas observações em M.E.V. sejam feitas em espécimes de $P$. magdalenensis para que a importância taxonômica das microtríquias seja avaliada em relação às demais espécies.

Entre todos os hospedeiros amostrados para este estudo, nenhum foi encontrado parasitado por P. magdalenensis, mesmo porque a área onde esta espécie ocorre (Rio Magdalena, Colômbia) não foi amostrada. Todos os espécimes disponíveis foram retirados de Potamotrygon magdalenae, hospedeiro tipo, restrito ao rio Magdalena, Colômbia, provenientes do material, ou parte, utilizado nas descrições e/ou redescrições deste táxon. O isolamento do rio Magdalena das demais drenagens sul-americanas devido ao soerguimento dos Andes pode ser responsável pelo endemismo de $P$. magdalenensis e seu hospedeiro (Marques et al., 2003). No entanto, há registros de parasitas de potamotrigonídeos que ocorrem no Rio Magdalena e outras bacias hidrográficas da América do Sul (Cardoso Jr., 2010), o que sugere que potencialmente P. magdalenensis poderia ser encontrada em 
outras localidades. Assim, temos que apenas amostragens mais amplas nas drenagens do norte da América do Sul poderão testar esta suposição.

Potamotrygonocestus travassosi Rego, 1979

(Figuras 6A-H e 7A-F)

Potamotrygonocestus travassosi Rego, 1979: Pag. 882, Figura4-6 (Holótipo CHIOC 31487a; parátipos CHIOC 31487 b-e, examinados); Brooks, Mayes \& Thorson, 1981: 48 (sp. ind.); Marques, Brooks \& Araújo, 2003: 337-380, Figuras 4-6 (redescr.).

Potamotrygonocestus orinocoensis Brooks, Mayes \& Thorson, 1981: 46-48, Figuras 3 e 4 (Holótipo USNPC 75713, examinado); Brooks, 1992: 589, Figura 1B (distribuição e biogeografia); Brooks \& Amato, 1992: 397 (especificidade); Marques, Brooks \& Araújo, 2003: 337-380, Figuras 4-6 syn. nov.

Redescrição: [baseada em 112 espécimes completos, 6 incompletos, 173 proglótides destacadas e 1 escólex observada em M.E.V.] Estróbilo acraspédoto, apolítico (Figura 6A); espécimes completos $0,81-7,82(2,83 \pm 1,13, \mathrm{n}=109) \mathrm{mm}$ de comprimento, compostos de 7-39 (23 \pm 7, $\mathrm{n}=105)$ proglótides. Escólex 140,94-414,19 (307,72 $\pm 65,95, \mathrm{n}=110) \times 180,09-446,31(278,11 \pm$ $51,92, n=110$ ) (Figura 6B), formada por quatro botrídeos não septados, cada um com uma ventosa apical e uma par de ganchos simples, coberta por espinitríquias gladiadas distribuídas entre filitríquias aciculares desde a região apical (Figura 7A). Botrídeo 110,20-304 (218,43 \pm 46,77, $\mathrm{n}=110) \times 76-201,43(132,62 \pm 26,78, \mathrm{n}=110)$ coberto proximalmente por espinitríquias gladiadas 1$4 / \mu \mathrm{m}^{2}(2,20 \pm 0,92, \mathrm{n}=10), 1,78-2,44(2,16 \pm 0,27, \mathrm{n}=6) \times 0,57-0,80(0,65 \pm 0,08, \mathrm{n}=6)$ (Figura 7B) distribuídas entre filitríquias aciculares e distalmente por espinitríquias gladiadas $1-2 / \mu \mathrm{m}^{2}(1,40 \pm$ 0,52, $\mathrm{n}=10)$ distribuídas entre filitríquias aciculares (Figura 7C). Ventosa apical 34,20-102,60 (70,47 $\pm 16,10, \mathrm{n}=110) \times 41,80-152(82,15 \pm 19,20, \mathrm{n}=110)$, coberta proximalmente por espinitríquias gladiadas $1-3 / \mu m^{2}(1,5 \pm 0,71, n=10), 0,91-1,07(1,07 \pm 0,97, n=3) \times 0,21-0,24(0,22 \pm 0,02, n=3)$ distribuídas entre filitríquias aciculares 10-11/ $\mu \mathrm{m}^{2} \quad(\mathrm{n}=2)$ (Figura 7D) e distalmente por espinitríquias gladiadas $1-2 / \mu \mathrm{m}^{2}(1,5 \pm 0,53, \mathrm{n}=10)$ distribuídas entre filitríquias aciculares (Figura 7E). Ganchos assimétricos (Figura 6C), gancho lateral 1,05-1,22 (1,03 $\pm 0,05, n=18)$ mais longo que o gancho medial; furca emergindo lateralmente da região posterior da base, revestido por tecido epitelial coberto por espinitríquias gladiadas exceto em sua extremidade, filitríquias aciculares observadas entre espinitríquias e até sua extremidade. Ganchos laterais 98,85-139,78 (117,79 \pm $12,98, n=22)$ de comprimento, base 37,82-60,20 (48,29 $\pm 4,88, n=22)$, furca 93,65-136,17 (109,61 \pm $11,48, \mathrm{n}=22)$, largura na furca 37,38-56,22 $(43,83 \pm 4,63, \mathrm{n}=22)$, base da furca $14,14-24,69(18,58 \pm$ $1,56, n=22)$, inserção da furca a partir de 54-67\% $(61 \pm 3, n=22)$ da base. Ganchos mediais 93,63$120,75(102,35 \pm 9,84, \mathrm{n}=25)$ de comprimento, base 37,04-62,46 $(50,66 \pm 5,54, \mathrm{n}=25)$, furca $65,74-$ 
A

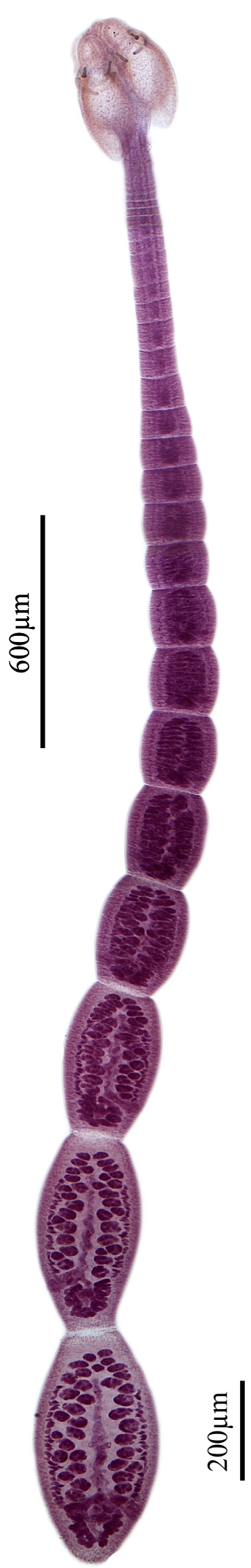

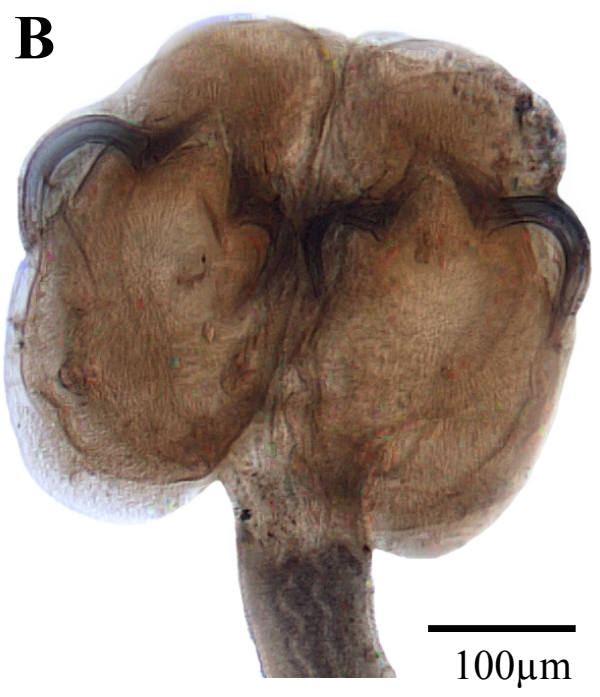

C
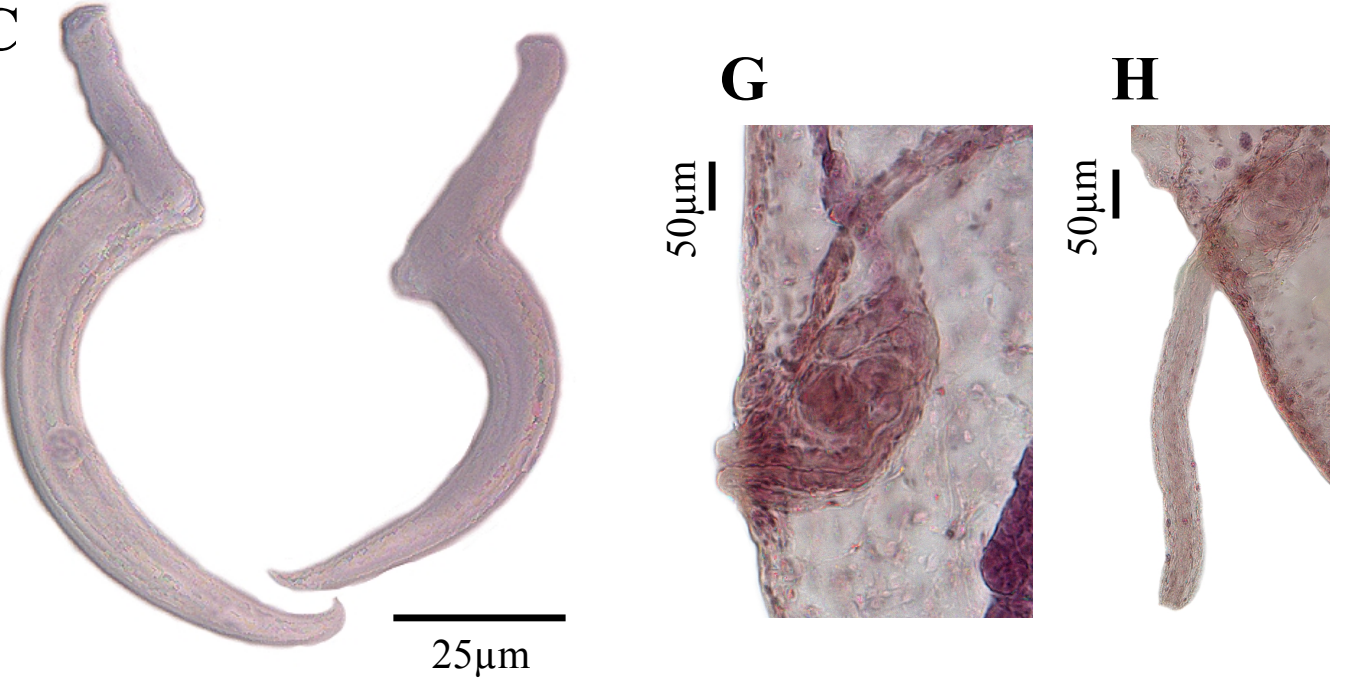
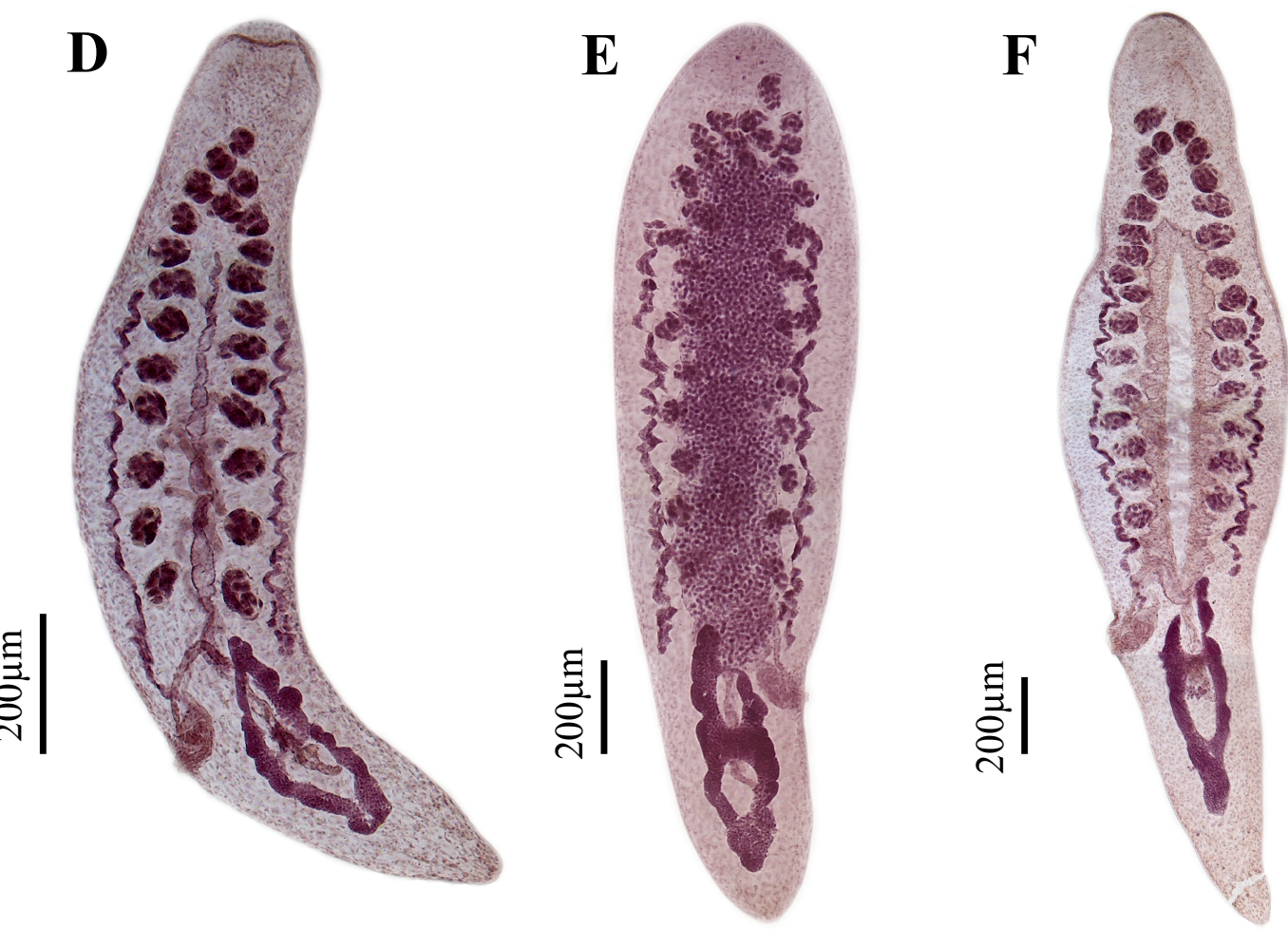

Figura 6. Potamotrygonocestus travassosi. A. Espécime completo (MZUSP 6981); B. Escólex (holótipo CHIOC 31487a); C. Ganchos (USNPC 75713); D. Proglótide madura (MZUSP 6974); E. Proglótide grávida (MZUSP 6992); F. Proglótide pós grávida (MZUSP 6974); G. Região do poro genital (MZUSP 6974); H. Cirro evertido (MZUSP 6974). 

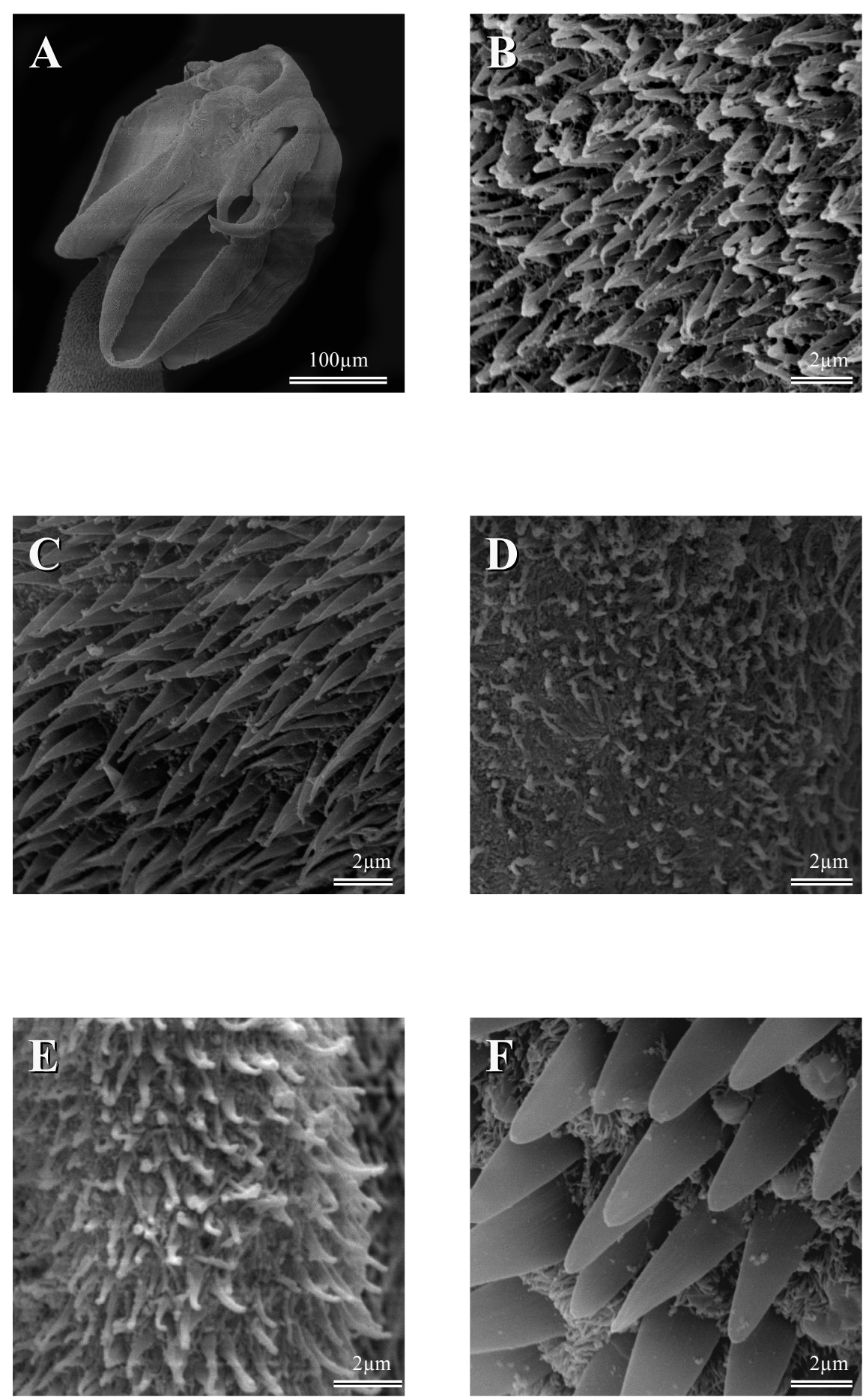

Figura 7. Potamotrygonocestus travassosi. M.E.V. A: Escólex. B: Região proximal do botrídeo C: Região distal do botrídeo. D: Região proximal da ventosa apical. E: Região distal da ventosa apical. F: Região de crescimento. 
$102,05(83,08 \pm 9,87, \mathrm{n}=25)$, largura na furca 25,55-44,11 (34,32 $\pm 4,94, \mathrm{n}=25)$, base da furca 12 $21,49(16,66 \pm 2,52, n=25)$, inserção da furca a partir de 56-78\% $(65 \pm 5, n=25)$ da base. Região de crescimento coberta por espinitríquias gladiadas distribuídas entre filitríquias aciculares (Figura 7F); espinitríquias gladiadas $0-1 / \mu \mathrm{m}^{2}(0,52 \pm 0,40, \mathrm{n}=10), 6,32-7,27(6,80 \pm 0,67, \mathrm{n}=2) \times 2,55-3,02$ $(2,79 \pm 0,33, n=2)$.

Proglótides imaturas 172,26-978,75 $(465,19 \pm 166,19, \mathrm{n}=85)$ x 93,96-305,37 (183,68 \pm 52,24, $\mathrm{n}=85)$; proglótides maduras não destacadas 234,90-1879,20 (608,23 $\pm 281,50, \mathrm{n}=53) \mathrm{x}$

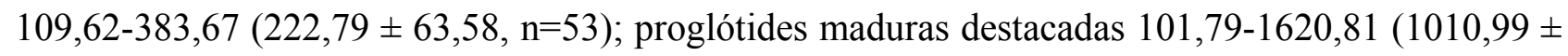
$320,51, \mathrm{n}=17) \times 219,24-391,24(285,10 \pm 46,74, \mathrm{n}=17)$ (Figura 6D); proglótides grávidas não destacadas 579,42-1511,19 (920,93 $\pm 301,32, \mathrm{n}=13) \times 180,09-336,69(265,02 \pm 49,81, \mathrm{n}=13)$; proglótides grávidas destacadas 783-3155,49 $(1740,15 \pm 528,08, \mathrm{n}=120)$ x 172,26-822,15 (441,87 \pm 116, $\mathrm{n}=120$ ) (Figura 6E); proglótides pós-grávidas 1025,73-2685,69 $(1609,76 \pm 402,63, \mathrm{n}=34) \mathrm{x}$ 274,05-587,25 (420,29 $\pm 80,03, \mathrm{n}=34)$ (Figura 6F). Testículos em duas colunas longitudinais anteriores ao ovário; testículos 14-44 (27 $\pm 6, \mathrm{n}=220)$ em número, 7-21 (13 $\pm 3, \mathrm{n}=220)$ poralmente, 7-23 (14 $\pm 3, \mathrm{n}=220)$ aporalmente; proglótides imaturas 14,77-61 $(30,94 \pm 8,67, \mathrm{n}=580) \times 21,10$ 63,44 (42,01 $\pm 8,75, \mathrm{n}=580)$; proglótides maduras não destacadas 14,77-92,84 (38,69 \pm 12,56, $\mathrm{n}=420) \times 29,28-73,20(51,32 \pm 7,88, \mathrm{n}=420)$; proglótides maduras destacadas 33,76-85,40 (57,54 \pm $10,96, \mathrm{n}=150) \times 42,20-85,40(60,37 \pm 8,47, \mathrm{n}=150)$; proglótides grávidas não destacadas 27,43$75,96(42,89 \pm 13,97, \mathrm{n}=40) \times 31,65-69,63(48,21 \pm 10,86, \mathrm{n}=40)$; proglótides grávidas destacadas 34,16-122,38 $(66,40 \pm 15,75, \mathrm{n}=240) \times 31,72-90,28(62,32 \pm 11,90, \mathrm{n}=240)$; proglótides pósgrávidas 36,60-73,20 (52,22 $\pm 10,36, \mathrm{n}=30) \times 39,04-97,60(67,91 \pm 18,39, \mathrm{n}=30)$. Poro genital póstero-lateral, anterior ou no mesmo nível do limite anterior dos lobos poral e aporal do ovário, podendo ultrapassar o istmo, não alcançando o limite posterior do ovário; átrio genital presente ou ausente (Figura 6G-H); 13-52\% $(25 \pm 6, \mathrm{n}=82)$ da margem posterior das proglótides imaturas não destacadas; $13-45 \%(23 \pm 5, \mathrm{n}=53)$ da margem posterior das proglótides maduras não destacadas; $11-34 \%(23 \pm 6, \mathrm{n}=17)$ da margem posterior das proglótides maduras destacadas; $18-33 \%$ (23 \pm 4 , $\mathrm{n}=13)$ da margem posterior das proglótides grávidas não destacadas; 5-50\% $(20 \pm 7, \mathrm{n}=120)$ da margem posterior das proglótides grávidas destacadas; 5-35\% $(20 \pm 8, \mathrm{n}=34)$ da margem posterior das proglótides pós grávidas destacadas. Vitelária em duas colunas laterais aos testículos, estendendo-se até o início do ovário, nunca ultrapassando o istmo ovariano. Ovário na porção terminal da proglótide, em forma de A, A invertido ou $\Theta$, simétrico ou assimétrico; proglótides imaturas 30,40-152 (77,01 $\pm 25,76, \mathrm{n}=79), 38-205,20(102,98 \pm 33,95, \mathrm{n}=79), 45,60-228(110,87 \pm$ 36,24, n=79); proglótides maduras não destacadas 41,80-212,80 (108,67 $\pm 37,47, \mathrm{n}=52), 60,80-304$ $(153,53 \pm 55,88, \mathrm{n}=52), 72,20-311,60(162,96 \pm 60,59, \mathrm{n}=52)$; proglótides maduras destacadas 
$45,60-155,80(102,85 \pm 28,63, n=15), 152-326,80(220,65 \pm 49,35, n=15), 152-349,60(237,12 \pm$

$61,13, \mathrm{n}=15)$; proglótides grávidas não destacadas 102,60-235,60 $(162,23 \pm 32,74, \mathrm{n}=13), 152$ 300,20 (239,11 $\pm 47,22, \mathrm{n}=13), 171-353,40(264,25 \pm 61,93, \mathrm{n}=13)$; proglótides grávidas destacadas $64,60-228(145,39 \pm 36,07, n=107), 152-729,60(356,84 \pm 120,30, n=107), 60,80-786,60(384,37 \pm$ 136,85, $\mathrm{n}=107)$; proglótides pós-grávidas 125,40-182,40 (154,85 $\pm 17,21, \mathrm{n}=8), 250,80-874(445,08$ $\pm 191,62, \mathrm{n}=8), 315,40-893(476,90 \pm 196,74, \mathrm{n}=8)$.

Hospedeiro tipo: Potamotrygon orbignyi (Castelnau, 1855) originalmente identificada como "Paratrygon histrix" em referência a Potamotrygon histrix (Müller \& Henle, 1834) (ver Brooks \& Amato, 1992).

Local de infecção: válvula espiral.

Localidade tipo: Rio Amazonas, Distrito de Maicuru, Monte Alegre, Pará, Brasil.

Localidades adicionais: Rio Arari, Igarapé Urubu, Baía do Marajó, Pará, Brasil (S 0 59' 58.20", O $48^{\circ} 57^{\prime}$ 52.55"); Rio Abacaxis, Comunidade Maruim, Borba, Amazonas, Brasil (S 4 ${ }^{\circ} 16^{\prime} 58.07^{\prime \prime}, \mathrm{O}$ $58^{\circ} 36^{\prime}$ 42.48"); Rio Negro, Lago do Boiador, Barcelos, Amazonas, Brasil (S 0 54' 24.11", O 62 58' 21.72"); Rio Negro, Boca do Cuiuní, Passagem do Tucupi, Barcelos, Amazonas, Brasil (S $0^{\circ} 46^{\prime}$ 41.88", O 63 8' 10.32"); Rio Negro, Paranã do Arirahá, Barcelos, Amazonas, Brasil (S 0 40' 23.16", O $63^{\circ} 12^{\prime}$ 7.56"); Rio Tapajós, Comunidade Piauí, Santarém, Pará, Brasil (S 2 17' 3.84", O $55^{\circ}$ 0' 13.67"); Paraná Janauacá, arredores de Manaus, Amazonas, Brasil (S 3 37', O 60²3'); Delta do Rio Orinoco, Arredores de El Toro, Venezuela.

Hospedeiros adicionais: Potamotrygon constellata (Vaillant, 1880), Potamotrygon motoro (Müller \& Henle, 1841), Potamotrygon scobina Garman, 1913, Potamotrygon cf. motoro, Potamotrygon sp_mar1; Potamotrygon cf. orbignyi.

Material examinado: Holótipo CHIOC 31487a; parátipos CHIOC 31487 b, e; USNM Helm. Coll.75713 (holótipo P. orinocoensis); USNM Helm. Coll. 75714 (parátipo P. orinocoensis). MZUSP 6974: 2 adult. imat., 6 progl. grav., 1 progl. mad., 5 progl. pgrav., em P. cf. motoro (AM07-05), Rio Abacaxis, Borba, Com. Maroin, Amazonas, Brasil; lat: -4.2828, long: -58.6118; dat: 10/01/07; col: F.P.L. Marques e M. Cardoso Jr. MZUSP 6975: 1 adult. , 7 adult. imat., 1 adult. incomp., em P. scobina (PA07-03), Baia de Marajó, Rio Tocantins, Colares, Pará, Brasil; lat: -0.9263, long: -48.2904; dat: 16/08/07; col: F.P.L. Marques, M. Cardoso Jr. e V.M. Bueno. MZUSP 6976: 1 adult. imat., em $P$. scobina (PA07-04), Baia de Marajó, Rio Tocantins, Colares, Pará, Brasil; lat: -0.9263, long: -48.2904; dat: 16/08/07; col: F.P.L. Marques, M. Cardoso Jr. e V.M. Bueno. MZUSP 6977: 2 adult. imat., em P. scobina (PA07-05), Baia de Marajó, Rio Tocantins, Colares, Pará, Brasil; lat: -0.9263, long: -48.2904; dat: 16/08/07; col: F.P.L. Marques, M. Cardoso Jr. e V.M. Bueno. MZUSP 6978: 2 adult. imat., em P. orbignyi (PA07-06), Baia de Marajó, Rio Tocantins, Colares, Pará, Brasil; lat: -0.9263, long: -48.2904; dat: 16/08/07; col: F.P.L. Marques, M. Cardoso Jr. e V.M. Bueno. MZUSP 6979: 1 adult. incomp., em P. scobina (PA07-07), Baia de Marajó, Rio Tocantins, Colares, Pará, Brasil; lat: -0.9263, long: -48.2904; dat: 16/08/07; col: F.P.L. Marques, M. Cardoso Jr. e V.M. Bueno. MZUSP 6980: 2 adult. imat., em P. orbignyi (PA07-10), Baia de Marajó, Rio Tocantins, Colares, Pará, Brasil; lat: -0.9263, long: -48.2904; dat: 16/08/07; col: F.P.L. Marques, M. Cardoso Jr. e V.M. Bueno. MZUSP 6981: 3 adult. , 4 adult. imat., 3 adult. mad., 4 progl. grav., 1 progl. mad., em P. scobina (PA07-16), Baia de Marajó, Rio Tocantins, Colares, Pará, Brasil; lat: -0.9263, long: -48.2904; dat: 18/08/07; col: F.P.L. Marques, M. Cardoso Jr. e V.M. Bueno. MZUSP 6982: 1 adult. , 1 adult. imat., em P. scobina (PA07-18), Baia de Marajó, Rio Tocantins, Colares, Pará, Brasil; lat: -0.9263, long: -48.2904; dat: 18/08/07; col: F.P.L. Marques, M. Cardoso Jr. e V.M. Bueno. MZUSP 6983: 1 adult. , 2 adult. imat., em P. scobina (PA07-19), Baia de Marajó, Rio Tocantins, Colares, Pará, Brasil; lat: -0.9263, long: -48.2904; dat: 18/08/07; col: F.P.L. Marques, M. Cardoso Jr. e V.M. Bueno. MZUSP 6984: 2 adult. imat., em P. orbignyi (PA07-20), Baia de Marajó, Rio Tocantins, Colares, Pará, Brasil; lat: -0.9263, long: -48.2904; dat: 20/08/07; col: F.P.L. Marques, M. Cardoso Jr. e V.M. Bueno. MZUSP 6985: 3 adult. imat., 9 adult. mad., em P. scobina (PA07-26), Baia de Marajó, Rio Tocantins, Colares, Pará, Brasil; lat: -0.9263, long: -48.2904; dat: 20/08/07; col: F.P.L. Marques, M. Cardoso Jr. e V.M. Bueno. MZUSP 6986: 1 adult. incomp., em P. scobina (PA07-32), Baia de Marajó, Rio Tocantins, Colares, Pará, Brasil; lat: -0.9263, long: -48.2904; dat: 20/08/07; col: F.P.L. Marques, M. Cardoso Jr. e V.M. Bueno. MZUSP 6987: 1 adult. imat., em $P$. orbignyi (PA07-33), Baia de Marajó, Rio Tocantins, Colares, Pará, Brasil; lat: -0.9263, long: -48.2904; dat: 21/08/07; col: F.P.L. Marques, M. Cardoso Jr. e V.M. Bueno. MZUSP 6988: 2 adult. imat., 4 progl. grav., em P. orbignyi (PA0734), Baia de Marajó, Rio Tocantins, Colares, Pará, Brasil; lat: -0.9263, long: -48.2904; dat: 21/08/07; col: F.P.L. Marques, M. Cardoso Jr. e V.M. Bueno. MZUSP 6989: 2 adult. , 13 adult. imat., 1 adult. mad., em P. orbignyi (PA07- 
35), Baia de Marajó, Rio Tocantins, Colares, Pará, Brasil; lat: -0.9263, long: -48.2904; dat: 21/08/07; col: F.P.L. Marques, M. Cardoso Jr. e V.M. Bueno. MZUSP 6990: 9 adult. grav., 2 adult. mad., 18 progl. grav., 5 progl. pgrav., em P. motoro (PA07-49), Baia de Marajó, Rio Arari, Ig. do Urubu, Cachoeira do Arari, Pará, Brasil; lat: -0.9995, long: -48.9646; dat: 28/08/07; col: F.P.L. Marques, M. Cardoso Jr. e V.M. Bueno. MZUSP 6991: 1 progl. grav., em P. motoro (PA07-56), Baia de Marajó, Rio Arari, Ig. do Urubu, Cachoeira do Arari, Pará, Brasil; lat: -0.9995, long: -48.9646; dat: 28/08/07; col: F.P.L. Marques, M. Cardoso Jr. e V.M. Bueno. MZUSP 6992: 1 adult. imat., 9 progl. grav., 1 progl. pgrav., em P. motoro (PA07-58), Baia de Marajó, Rio Arari, Ig. do Urubu, Cachoeira do Arari, Pará, Brasil; lat: -0.9995, long: -48.9646; dat: 28/08/07; col: F.P.L. Marques, M. Cardoso Jr. e V.M. Bueno. MZUSP 6993: 1 adult. imat., 4 progl. grav., 2 progl. mad., em P. motoro (PA07-71), Baia de Marajó, Rio Arari, Ig. do Urubu, Cachoeira do Arari, Pará, Brasil; lat: -0.9995, long: -48.9646; dat: 28/08/07; col: F.P.L. Marques, M. Cardoso Jr. e V.M. Bueno. MZUSP 6994: 2 adult. imat., 3 progl. grav., 1 progl. mad., em P. motoro (PA07-73), Baia de Marajó, Rio Arari, Ig. do Urubu, Cachoeira do Arari, Pará, Brasil; lat: -0.9995, long: -48.9646; dat: 28/08/07; col: F.P.L. Marques, M. Cardoso Jr. e V.M. Bueno. MZUSP 6995: 1 adult. imat., 1 progl. grav., em P. motoro (PA07-77), Baia de Marajó, Rio Arari, Ig. do Urubu, Cachoeira do Arari, Pará, Brasil; lat: -0.9995, long: -48.9646; dat: 29/08/07; col: F.P.L. Marques, M. Cardoso Jr. e V.M. Bueno. MZUSP 6996: 1 adult. , 1 adult. imat., em P. motoro (PA07-78), Baia de Marajó, Rio Arari, Ig. do Urubu, Cachoeira do Arari, Pará, Brasil; lat: -0.9995, long: -48.9646; dat: 29/08/07; col: F.P.L. Marques, M. Cardoso Jr. e V.M. Bueno. MZUSP 6997: 12 progl. grav., 3 progl. mad., 2 progl. pgrav., em P. motoro (RN05-04), Rio Negro, Lago do Boiador, Barcelos, Amazonas, Brasil; lat: -0.9067, long: -62.9727; dat: 23/01/05; col: M.V. Domingues, N.M. Luchetti e S. Mello. MZUSP 6998: 2 adult. incomp., 1 adult. mad., em P. motoro (RN05-69), Rio Negro, Boca do Cuiuní, Passagem do Tucupi, Barcelos, Amazonas, Brasil; lat: -0.7783, long: -63.1362; dat: 02/02/05; col: M.V. Domingues, N.M. Luchetti e S. Mello. MZUSP 6999: 5 progl. grav., 6 progl. mad., 9 progl. pgrav., em P. motoro (RN05-71), Rio Negro, Boca do Cuiuní, Passagem do Tucupi, Boca do Matena, Barcelos, Amazonas, Brasil; lat: -0.7783, long: -63.1362; dat: 02/02/05; col: M.V. Domingues, N.M. Luchetti e S. Mello. MZUSP 7000: 1 adult. imat., 1 progl. grav., em P. motoro (RN05-77), Rio Negro, Boca do Cuiuní, Barcelos, Amazonas, Brasil; lat: -0.7783, long: -63.1362; dat: 02/02/05; col: M.V. Domingues, N.M. Luchetti e S. Mello. MZUSP 7001: 5 progl. grav., 1 progl. pgrav. copula , em $P$. motoro (RN05-79), Rio Negro, Paranã do Arirahá, Barcelos, Amazonas, Brasil; lat: -0.6731, long: -63.2021; dat: 03/02/05; col: M.V. Domingues, N.M. Luchetti e S. Mello. MZUSP 7002: 2 adult. imat., 4 adult. mad., 5 progl. grav., em P. motoro (RN05-80), Rio Negro, Paranã do Arirahá, Barcelos, Amazonas, Brasil; lat: -0.6731, long: -63.2021; dat: 03/02/05; col: M.V. Domingues, N.M. Luchetti e S. Mello. MZUSP 7003: 1 adult. imat., 2 progl. grav., 1 progl. mad., em P. motoro (RN05-82), Rio Negro, Rio Arirahá, Boca do Jacaré, Barcelos, Amazonas, Brasil; lat: -0.6731, long: -63.2021; dat: 04/02/05; col: M.V. Domingues, N.M. Luchetti e S. Mello. MZUSP 7004: 1 adult. incomp., em $P$. motoro (RN05-83), Rio Negro, Rio Arirahá, Boca do Jacaré, Barcelos, Amazonas, Brasil; lat: -0.6731, long: -63.2021; dat: 04/02/05; col: M.V. Domingues, N.M. Luchetti e S. Mello. MZUSP 7005: 4 progl. grav., em P. motoro (RN05-84), Rio Negro, Rio Arirahá, Boca do Jacaré, Barcelos, Amazonas, Brasil; lat: -0.6731, long: -63.2021; dat: 04/02/05; col: M.V. Domingues, N.M. Luchetti e S. Mello. MZUSP 7006: 1 adult. imat., em P. motoro (RN05-85), Rio Negro, Rio Arirahá, Boca do Jacaré, Barcelos, Amazonas, Brasil; lat: -0.6731, long: -63.2021; dat: 04/02/05; col: M.V. Domingues, N.M. Luchetti e S. Mello. MZUSP 7007: 9 progl. grav., 1 progl. mad., em P. motoro (RN05-86), Rio Negro, Rio Arirahá, Boca do Jacaré, Barcelos, Amazonas, Brasil; lat: -0.6731, long: -63.2021; dat: 04/02/05; col: M.V. Domingues, N.M. Luchetti e S. Mello. MZUSP 7008: 1 adult. mad., 4 progl. grav., 1 progl. pgrav., em P. motoro (RN05-87), Rio Negro, Rio Arirahá, Lago do Juraci, Barcelos, Amazonas, Brasil; lat: -0.6731, long: -63.2021; dat: 04/02/05; col: M.V. Domingues, N.M. Luchetti e S. Mello. MZUSP 7009: 3 adult., 3 adult. imat., 1 adult. mad., 12 progl. grav., 2 progl. pgrav., em P. orbignyi (TJ05-05), Tapajós, Comunidade Piauí, Santarém, Pará, Brasil; lat: -2.2844, long: -55.0038; dat: 03/10/05; col: M.R. Carvalho, M. Cardoso Jr., M.L.G. Araújo, S. Mello. MZUSP 7010: 1 adult., 1 adult. grav., 6 adult. imat., 3 adult. mad., 12 progl. grav., 1 progl. mad., 8 progl. pgrav., em P. orbignyi (TJ05-25), Tapajós, Comunidade Piauí, Santarém, Pará, Brasil; lat: -2.2844, long: -55.0038; dat: 04/10/05; col: M.R. Carvalho, M. Cardoso Jr., M.L.G. Araújo, S. Mello.

\section{Considerações taxonômicas:}

A descrição de Potamotrygonocestus travassosi por Rego (1979) baseou-se principalmente nas características do escólex, pois os espécimes disponíveis estavam imaturos. Em 1981, Brooks et al. consideraram P. travassosi species inquirenda, pois observaram várias inconsistências entre a descrição e as figuras apresentadas por Rego (1979) que sugeriam que o autor misturou espécimes de linhagens distintas para formalizar seu conceito de P. travassosi. Entre estas inconsistências, havia a inclusão de uma proglótide do tripanorinquídeo Paraoncomegas araya Woodland, 1934 na 
descrição da espécie (ver Marques et al., 2003). Brooks et al. (1981) não examinaram nenhum exemplar da série tipo de $P$. travassosi e conceberam $P$. orinocoensis para receber espécimens coletados em Potamotrygon orbignyi (syn. P. reticulatus; Carvalho et al., 2003) do Rio Orinoco, na Venezuela. De acordo com estes autores, P. orinocoensis possuía atributos que permitiam sua diagnose como a formação da vitelária e ausência de átrio genital, além de notar que a forma de seu ovário, em $\Theta$, era única. Além disso, espécie diferia de $P$. magdalenensis e de $P$. amazonensis devido a morfologia de seus ganchos e posição do poro genital.

Marques et al. (2003) revalidaram $P$. travassosi, baseando-se na série tipo e em novos espécimes coletados no hospedeiro tipo. O holótipo de P. travassosi (CHIOC 31487a) e dois parátipos (CHIOC 31487 b,e) permitiram o reconhecimento de P. travassosi como espécie válida, sendo os demais (CHIOC 31487 c,d) pertencentes a Paraoncomegas araya. Esta redescrição incluiu registros de outros hospedeiros para P. travassosi (Paratrygon aiereba, Potamotrygon constellata e Potamotrygon motoro) e novas localidades, ampliando a distribuição biogeográfica conhecida da espécie. O aumento do número de indivíduos amostrados ampliou o intervalo dos parâmetros morfométricos para a espécie não permitindo diferenciar $P$. travassosi de $P$. orinocoensis e justificando a sinonímia destas duas espécies (Marques et al., 2003), além de mostrar que a morfologia em $\Theta$ do ovário não era um caráter consistente.

O conceito de P. travassosi s. str. adotado neste estudo também inclui membros do gênero que anteriormente haviam sido incluídos em outra espécie. O exame dos espécimes parasitas de Potamotrygon motoro coletados no Rio Negro e atribuídos a $P$. fitzgeraldae por Marques et al. (2003) revelou que os indivíduos não pertenciam a esta espécie, mas sim a $P$. travassosi. Esta diferenciação foi baseada na morfologia do gancho, redescrita neste trabalho para ambas espécies (ver descrição de P. fitzgeraldae adiante).

Os dados morfométricos e merísticos obtidos para $P$. travassosi não permitem diagnosticar esta espécie das demais atribuídas ao gênero, pois há sobreposição de valores (Anexo I). Adicionalmente, a morfologia das microtríquias em M.E.V. mostrou que estas estruturas não possuem variação interespecífica (Anexo II). Entre as características discretas observadas, somente a morfologia do gancho é diagnóstica para esta espécie. O gancho lateral apresenta furca arredondada, sem angulações, com extremidade distal curva, voltada para a base (Figura 6B, C), enquanto o gancho medial tem furca arredondada, com angulação na altura da inserção da furca na base e extremidade distal voltada para o lado (Figura 6B, C). Ganchos lateral e medial apresentam base com valores aproximados (37,82-60,20 vs. 37,04-62,46) e largura da base da furca mantém-se constante pelo comprimento diminuindo apenas a partir de 1/3 distal (Figura 6C). Os espécimes utilizados na descrição de $P$. orinocoensis (USNPC 75713 e 75714) também apresentam esta 
morfologia no gancho, corroborando a sinonímia de Marques et al. (2003).

Potamotrygonocestus travassosi difere de $P$. magdalenensis pela morfologia de seus ganchos. Em P. travassosi a inserção da furca é na região postero-lateral da base do gancho, enquanto em $P$. magdalenensis possui inserção da furca na região centro-lateral da base do gancho. Potamotrygonocestus travassosi ainda difere de P. magdalenensis por apresentar poro genital anterior ou no mesmo nível do ovário e não posterior ao ovário como a espécie tipo do gênero.

Espécimes de $P$. travassosi foram coletados parasitando 7 diferentes morfotipos de potamotrigonídeos, apresentando baixa especificidade parasita-hospedeiro. Nenhum espécime de $P$. travassosi foi observado nas drenagens dos rios Paraguai, Paraná e Uruguai, restringindo a distribuição da espécie às bacias hidrográficas Alto Amazonas, Baixo Amazonas, Negro/Branco e Orinoco. Os espécimes disponíveis foram coletados desde o delta do rio Orinoco, Venezuela, até a Baía de Marajó, PA, Brasil, apresentando ampla distribuição longitudinal para a espécie.

Potamotrygonocestus amazonensis Mayes, Brooks \& Thorson, 1981

(Figura 8A-G)

Potamotrygonocestus amazonensis Mayes, Brooks \& Thorson, 1981: 40-42, Figura 5-7 (descr., Holótipo USNM 76361, examinado); Brooks, Mayes \& Thorson, 1981: 48, Figura 5 (diagnose e filogenia); Brooks, 1992: 598 (distribuição e biogeografia); Brooks \& Amato 1992: 397 (especificidade); Marques, Brooks \& Araújo, 2003:371-377, Figuras 2-3 (redescr.).

Redescrição: [baseada em 36 espécimes adultos completos, 2 espécimes adultos incompletos e 33 proglótides destacadas] Estróbilo acraspédoto, apolítico (Figura 8A); espécimes completos 0,34-2,58 (1,36 $\pm 0,51, \mathrm{n}=36) \mathrm{mm}$ de comprimento, compostos de 4-19 (11 $\pm 3, \mathrm{n}=34)$ proglótides. Escólex 180,09-391,50 (285,48 \pm 39,26, n=37) x 172,26-321,03 (235,96 \pm 35,94, n=37) (Figura 8B), formada por quatro botrídeos não septados, cada um com uma ventosa apical e um par de ganchos simples. Botrídeo 152-345,80 (249,01 $\pm 41,92, \mathrm{n}=34)$ x 87,40-152 (112,99 $\pm 14,44, \mathrm{n}=34)$. Ventosa apical 19-53,20 $(31,92 \pm 8,33, \mathrm{n}=30) \times 30,40-53,20(41,42 \pm 5,93, \mathrm{n}=30)$. Ganchos simétricos (Figura 8C), gancho lateral 1,09 $(\mathrm{n}=1)$ do comprimento do gancho medial; furca emergindo lateralmente da região central da base. Ganchos laterais 57,43-79,41 (70,54 $\pm 10,21$, $\mathrm{n}=4)$ de comprimento, base 21,07-35,30 (28,46 $\pm 6,61, \mathrm{n}=4)$, furca 70,61-92,27 (84,54 $\pm 8,56, \mathrm{n}=5)$, largura na furca 29,28-41,26 $(35,85 \pm 5,09, n=5)$, base da furca 9-12 $(10,98 \pm 1,22, n=5)$, inserção da furca a partir de 30-48\% $(40 \pm 8, \mathrm{n}=4)$ da base. Ganchos mediais 48,20-62,13 (56,43 $\pm 7,3, \mathrm{n}=3)$ de comprimento, base 19,68-22,60 (21,23 $\pm 1,47, n=3)$, furca 57,12-90,06 $(72,33 \pm 16,61, n=3)$, largura na furca 25,97-40,99 $(31,27 \pm 8,43, \mathrm{n}=3)$, base da furca 9,19-11,6 $(10,31 \pm 1,21, \mathrm{n}=3)$, inserção da furca a partir de $28-47 \%(36 \pm 1, n=3)$ da base. 

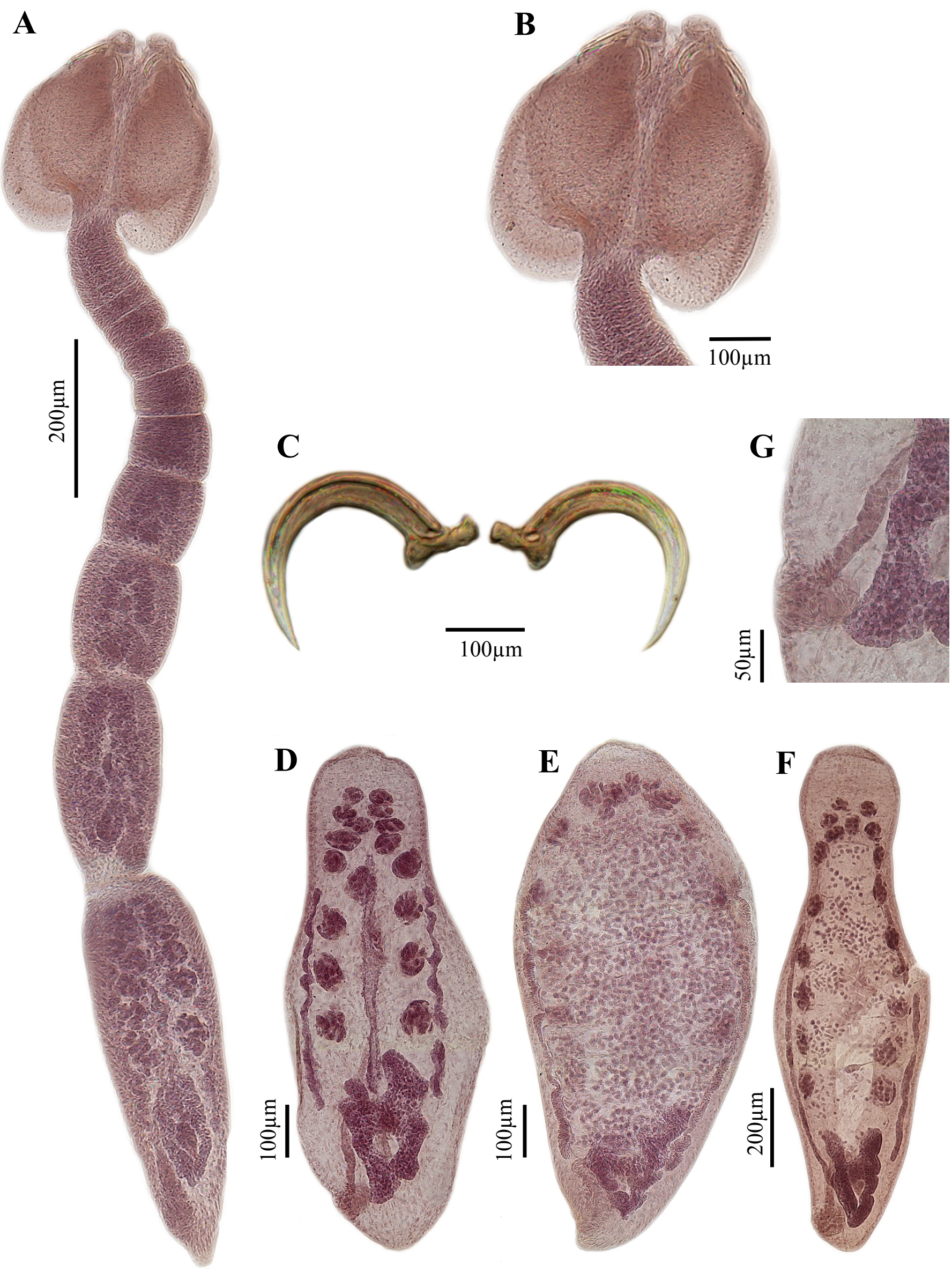

Figura 8. Potamotrygonocestus amazonensis. A. Espécime completo (MZUSP 7013); B. Escólex (MZUSP 7013); C. Ganchos (holótipo USNPC 76363); D. Proglótide madura (MZUSP 7016); E. Proglótide grávida (MZUSP 7015); F. Proglótide pós grávida (MZUSP 7017); G. Região do poro genital (MZUSP 7016). 
Proglótides imaturas 140,94-626,40 (315,73 $\pm 123,25, \mathrm{n}=31) \times$ 70,47-325,35 (161,40 \pm 52,51, $\mathrm{n}=31)$; proglótides maduras não destacadas 195,75-665,55 (416,19 $\pm 130,34, \mathrm{n}=26)$ x 133,11344,52 (193,64 $\pm 41,99, \mathrm{n}=26)$; proglótides maduras destacadas 751,68-1025,73 $(853,47 \pm 104,02$, $\mathrm{n}=5) \times$ 250,56-368,01 (310,07 $\pm 44,50, \mathrm{n}=5)$ (Figura 8D); proglótide grávida não destacada 540,27 $(\mathrm{n}=1) \times 234,9(\mathrm{n}=1)$; proglótides grávidas destacadas 681,21-2740,50 $(1265,85 \pm 519,83, \mathrm{n}=24) \times$ 281,88-540,27 (405,53 \pm 67,79, $\mathrm{n}=24)$ (Figura 8E); proglótides pós-grávidas 861,30-1879,20 $(1289,99 \pm 434,42, n=4) \times 352,35-399,33(373,88 \pm 25,07, n=4)$ (Figura 8F). Testículos em duas colunas longitudinais anteriores ao ovário; testículos 12-23 (17 $\pm 3, \mathrm{n}=71)$ em número, 6-12 (8 \pm 2 , $\mathrm{n}=71)$ poralmente, $5-12(8 \pm 2, \mathrm{n}=71)$ aporalmente; proglótides imaturas $12,20-6832(31,10 \pm 11,26$, $\mathrm{n}=190) \times 19,52-68,32(44,52 \pm 10,95, \mathrm{n}=190)$; proglótides maduras não destacadas 14,64-78,08 $(37,37 \pm 11,56, \mathrm{n}=220) \times 24,40-73,20(50,12 \pm 10,29, \mathrm{n}=220)$; proglótides maduras destacadas 14,64-78,08 $(58,36 \pm 13,93, \mathrm{n}=50) \times 41,48-85,40(58,90 \pm 9,67, \mathrm{n}=50)$; proglótides grávidas destacadas 34,16-78,08 $(53,40 \pm 12,56, \mathrm{n}=60) \times 34,16-90,28(57,06 \pm 14,13, \mathrm{n}=60)$; proglótides pós-grávidas 58,56-85,40 $(71,74 \pm 9,50, \mathrm{n}=10) \times 53,68-85,40(69,54 \pm 9,84, \mathrm{n}=10)$. Poro genital postero-lateral no mesmo nível do limite posterior dos lobos ovarianos ou posterior ao ovário; átrio genital presente ou ausente (Figura 8G); 3-21\% $(9 \pm 4, n=23)$ da margem posterior das proglótides imaturas não destacadas; $1,7-15 \%(7 \pm 4, \mathrm{n}=26)$ da margem posterior das proglótides maduras não destacadas; 4-23\% $(11 \pm 8, \mathrm{n}=5)$ da margem posterior das proglótides maduras destacadas; 4\% $(\mathrm{n}=1)$ da margem posterior das proglótides grávidas não destacadas; $1,4-8 \%(5 \pm 2, n=24)$ da margem posterior das proglótides grávidas destacadas; $2-7 \%(5 \pm 2, \mathrm{n}=4)$ da margem posterior das proglótides pós grávidas destacadas. Vitelária em duas colunas laterais aos testículos, estendendo-se até o início do ovário, nunca ultrapassando o istmo ovariano. Ovário na porção posterior da proglótide, em forma de $\mathrm{A}$ invertido ou $\Theta$, simétrico ou assimétrico; proglótides imaturas 38-133 $(68,22 \pm 20,73, \mathrm{n}=21), 41,80-152(95,90 \pm 36,27, \mathrm{n}=21), 41,80-152 \quad(96,99 \pm 37,17, \mathrm{n}=21)$; proglótides maduras não destacadas 49,40-148,20 (85,43 $\pm 21,40, \mathrm{n}=27), 53,20-292,60(138,77 \pm$ 60,66, $\mathrm{n}=27), 53,20-292,60(137,64 \pm 60,43, \mathrm{n}=27)$; proglótides maduras destacadas 76-121,60 $(102,60 \pm 17,82, \mathrm{n}=5), 95-323(201,40 \pm 85,01, \mathrm{n}=5), 140,60-269,80 \quad(200,64 \pm 52,96, \mathrm{n}=5)$; proglótide grávida não destacada 91,20 $(\mathrm{n}=1), 174,80(\mathrm{n}=1)$ x 174,80 $(\mathrm{n}=1)$; proglótides grávidas destacadas 114-220,40 (1554,97 $\pm 29,21, n=23), 152-452,20(260,88 \pm 65,77, n=23), 178,60-452,20$ $(270,30 \pm 71,11, \mathrm{n}=23)$; proglótides pós-grávidas $114-144,40(129,20 \pm 15,51, \mathrm{n}=4), 220,40-330,60$ $(274,55 \pm 48,70, \mathrm{n}=4), 228-330,60(276,45 \pm 45,95, \mathrm{n}=4)$.

Hospedeiro tipo: Potamotrygon orbignyi (Castelnau, 1855).

Local de infecção: válvula espiral.

Localidade tipo: Rio Itacuaí, $5 \mathrm{~km}$ ao sul de Atalaia do Norte, Amazonas, Brasil.

Localidades adicionais: Rio Abacaxis, Comunidade Maroin, Borba, Amazonas (S 4 16' 58.07", W 
$58^{\circ} 36^{\prime}$ 42.48"); Rio Negro, Paranã do Bafuana, Barcelos, Amazonas, Brasil (S $0^{\circ} 54^{\prime} 24.11^{\prime \prime}$, O $62^{\circ}$ $58^{\prime}$ 21.72"); Rio Negro, Rio Demení, Lago Maqui, Barcelos, Amazonas, Brasil (S 0 42' 42.83", O $\left.62^{\circ} 59^{\prime} 35.87 "\right)$; Rio Tocantins, confluência do Rio Manuel Alves, Ipueiras, Tocantins, Brasil (S $11^{\circ}$ 15' 48.52", O 48 26' 56.79"); Rio Araguaia, Caseara, Tocantins, Brasil (S 9 16' 11.66", O 49 58' 18.70"); Rio Xingu, São Félix do Xingu, Pará, Brasil (S 6 39' 23.33", O 51 59' 56.72").

Hospedeiros adicionais: Potamotrygon humerosa Garman, 1913; Potamotrygon sp_toc3; Potamotrygon sp_cururu.

Material examinado: USNM Helm. Coll. 76363 (holótipo). MZUSP 7011: 1 adult. imat., em P. humerosa (AM07-01), Rio Abacaxis, Borba, Com. Maroin, Amazonas, Brasil; lat: -4.2828, long: -58.6118; dat: 09/01/07; col: F.P.L. Marques e M. Cardoso Jr. MZUSP 7012: 2 adult. imat., 2 progl. grav., 1 progl. mad., em P. humerosa (AM0703), Rio Abacaxis, Borba, Com. Maroin, Amazonas, Brasil; lat: -4.2828, long: -58.6118; dat: 08/01/07; col: F.P.L. Marques e M. Cardoso Jr. MZUSP 7013: 8 adult. imat., 2 adult. mad., 1 progl. grav., 1 progl. mad., em P. humerosa (AM07-06), Rio Abacaxis, Borba, Com. Maroin, Amazonas, Brasil; lat: -4.2828, long: -58.6118; dat: 11/01/07; col: F.P.L. Marques e M. Cardoso Jr. MZUSP 7014: 1 adult., 2 adult. imat., 3 adult. mad., 1 progl. grav., 2 progl. pgrav., em P. humerosa (AM07-08), Rio Abacaxis, Borba, Com. Maroin, Amazonas, Brasil; lat: -4.2828, long: -58.6118; dat: 12/01/07; col: F.P.L. Marques e M. Cardoso Jr. MZUSP 7015: 1 adult., 1 adult. , 7 adult. mad., 12 progl. grav., 1 progl. mad., em P. humerosa (AM07-21), Rio Abacaxis, Borba, Com. Maroin, Amazonas, Brasil; lat: -4.2828, long: -58.6118; dat: 26/01/07; col: F.P.L. Marques e M. Cardoso Jr. MZUSP 7016: 1 adult. imat., 2 progl. mad., em P. orbignyi (RN0404), Rio Negro, Rio Demení, Lago Maqui, Barcelos, Amazonas, Brasil; lat: -0.7119, long: -62.9933; dat: 23/02/04; col: F.P.L. Marques. M.L.G. Araújo. MZUSP 7017: 1 progl. pgrav., em P. orbignyi (RN05-41), Rio Negro, Molongozal, Barcelos, Amazonas, Brasil; lat: -0.9067, long: -62.9727; dat: 27/01/05; col: M.V. Domingues, N.M. Luchetti e S. Mello. MZUSP 7018: 1 adult. mad., 8 progl. grav., 1 progl. pgrav., em P. sp_toc3 (TO05-21), Rio Tocantins, confluência do Rio Manuel Alves, Ipueiras, Tocantins, Brasil; lat: -11.2635, long: -48.4491; dat: 12/06/05; col: F.P.L. Marques, M.V. Domingues e J. Mattox. MZUSP 7019: 3 adult. imat., em P. sp_toc3 (TO05-43), Rio Araguaia, Caseara, Tocantins, Brasil; lat: -9.2699, long: -49.9719; dat: 25/06/05; col: F.P.L. Marques, M.V. Domingues e J. Mattox. MZUSP 7020: 1 adult. imat., em P. orbignyi (TO05-51), Rio Araguaia, Caseara, Tocantins, Brasil; lat: -9.2699, long: -49.9719; dat: 26/06/05; col: F.P.L. Marques, M.V. Domingues e J. Mattox. MZUSP 7021: 1 adult. grav., 3 adult. mad., em P. orbignyi (TO05-74), Rio Xingú, São Felix do Xingú, Pará, Brasil; lat: -6.6565, long: -51.9990; dat: 03/07/05; col: F.P.L. Marques, M.V. Domingues e J. Mattox.

\section{Considerações taxonômicas:}

$\mathrm{Na}$ mais recente revisão taxonômica para o gênero Potamotrygonocestus, Marques et al. (2003) consideraram que $P$. amazonensis possuía uma ampla distribuição geográfica. Para estes autores, a espécie poderia ser encontrada nas bacias hidrográficas do rio Paraguai e Amazônica; embora as diferentes populações encontradas nestas bacias apresentaram variações morfométricas conspícuas, o que indicaria a possibilidade de que $P$. amazonensis ser um complexo de espécies. A reavaliação do material utilizado por Marques et al. (2003), bem como o material tipo desta espécie, revelou que o conceito de $P$. amazonensis destes autores inclui duas linhagens distintas, uma em cada bacia hidrográfica, e que diferem na morfologia do gancho e posição relativa do poro genital. De acordo com o material disponível atribuído inicialmente a esta espécie, indivíduos coletados na região Amazônica possuem ganchos arredondados (Figura 8C) e poro genital posterior aos lobos ovarianos (Figura 8D, E, F), ao passo que aqueles provenientes da bacia do Prata possuem ganchos angulados e poro genital no nível do ovário.

Marques et al. (2003) observaram quatro morfologias distintas de ganchos (Marques et al., 2003; 372: Figura 2B-G) entre diferentes populações de P. amazonensis. Dentre os morfotipos ilustrados por estes autores, apenas um é congruente com a morfologia do holótipo de $P$. 
amazonenesis (USNM 76363), possuindo ganchos arredondados (Figura 8C). Espécimes de $P$. amazonensis coletados em Potamotrygon orbignyi provenientes do rio Tocantins estão em conformidade com a morfologia do gancho do holótipo desta espécie. No entanto, os registros desta espécies para o Rio Negro, parasitando Potamotrygon sp. não puderam ser determinados, pois os exemplares preparados por Marques et al. (2003) apresentavam ganchos inclinados e novas amostras de potamotrigonídeos do Rio Negro resultaram apenas na obtenção de proglótides livres. Desta forma, parte da variabilidade na morfologia do gancho atribuída para esta espécie é resultado da inclusão inapropriada de exemplares cuja a posição do gancho não permitiam documentar sua forma sem ambiguidade. Finalmente, indivíduos coletados em Potamotrygon motoro provenientes do Rio Paraguai (Corumbá/MT, CHIOC 32816 b, e) apresentam morfologia do gancho diferente do holótipo de P. amazonensis e foram consideradas membros de uma linhagem independente neste estudo (veja abaixo).

Como observado até o momento para as demais espécies de Potamotrygonocestus, os parâmetros morfométricos obtidos para P. amazonensis s. str. (i.e., encontrados na bacia Amazônica) apresentaram sobreposição de valores com as demais espécies do gênero (Anexo I). Os caracteres relacionados à morfologia das microtríquias do escólex e cirro não puderam ser avaliados devido à indisponibilidade de espécimes para análises de M.E.V. para esta espécie. Dentre os atributos morfológicos e morfométricos examinados, o único caráter discreto que permite a diagnose de P. amazonensis s. str. é a morfologia dos ganchos. Desta forma, P. amazonensis s. str. que possui ganchos com furcas de simetria semelhante, arredondadas e sem angulações, com largura da furca diminuindo conforme se aproxima à extremidade distal (Figura 8C) pode ser diferenciada de $P$. magdalenensis e de $P$. travassosi, pois a primeira apresenta ganchos assimétricos com gancho lateral arredondado e gancho medial com angulação (Figura 5C) e a segunda possui furca inserida lateralmente na região posterior da base e gancho lateral arredondado e gancho medial com angulação (Figura 6C). Finalmente, P. amazonensis s. str. pode ainda ser distinguido de P. travassosi na posição do poro genital (no nível do limite posterior dos lobos ovarianos ou posterior ao ovário $v s$. anterior ou no mesmo nível do ovário (Figura $8 \mathrm{D}, \mathrm{E}, \mathrm{F}$ ) .

A circunscrição mais restrita de $P$. amazonensis s. str. redefine a distribuição geográfica desta espécie. Este novo conceito restringe a espécie aos sistemas fluviais da região Amazônica. Os registros desta espécie para as demais bacias sul americanas (i.e., Paraguai, Paraná e Uruguai) serão atribuídos a uma nova espécie para o gênero (ver abaixo). Com relação à especificidade aos hospedeiros, P. amazonensis s. str. é encontrada em quatro morfotipos de Potamotrygon (i.e., $P$. orbignyi, $P$. humerosa, $P$. sp_cururu e $P$. sp_toc3). Vale ressaltar que o padrão de infestação de $P$. amazonensis s. str. é peculiar por apresentar co-ocorrência com outra espécie do gênero: 
Potamotrygonocestus maurae Marques, Brooks \& Araújo, 2003. Ambas foram coletadas compartilhando indivíduos de Potamotrygon humerosa no rio Abacaxis (AM) e de P. orbignyi no rio Negro (AM). Este padrão de infestação não havia sido registrado anteriormente para o gênero.

Potamotrygonocestus maurae Marques, Brooks \& Araujo, 2003

(Figura 9A-G e 10A-I)

Potamotrygonocestus maurae: Marques, Brooks \& Araujo, 2003: 388-390, Figura 10 (descr. Holótipo MZUSP 5854, examinado).

Redescrição: [baseada em 139 espécimes completos, 4 espécimes incompletos, 108 proglótides destacadas e 4 escóleces observadas em M.E.V.] Estróbilo acraspédoto, apolítico (Figura 9A); espécimes completos 0,60-2,99 (1,12 $\pm 0,37, \mathrm{n}=121) \mathrm{mm}$ de comprimento, compostos de 6-26 (11 $\pm 3, \mathrm{n}=123)$ proglótides. Escólex 219,24-383,67 $(275,35 \pm 27,11, \mathrm{n}=133)$ x 180,09$328,86(259,26 \pm 26,16, n=133)$ (Figura 9B), formada por 4 botrídeos não septados, cada um com uma ventosa apical e um par de ganchos simples, coberta por filitríquias aciculares na região apical (Figura 10A,B). Botrídeo 152-304 (234,62 $\pm 26,49, \mathrm{n}=128)$ x 79,80-167,20 (125,67 $\pm 16,09, \mathrm{n}=129)$ coberto proximalmente por espinitríquias gladiadas, $2-4 / \mu \mathrm{m}^{2}(3 \pm 1, \mathrm{n}=10), 0,96-1,33(1,14 \pm 0,10$, $\mathrm{n}=20)$ de comprimento, 0,37-0,50 $(0,44 \pm 0,04, \mathrm{n}=20)$ de largura na base, distribuídas entre filitríquias aciculares 0,40-0,58 (0,53 $\pm 0,06, \mathrm{n}=8)$ de comprimento, 0,08-0,12 $(0,11 \pm 0,02, \mathrm{n}=8)$ de largura na base (Figura 10C,D) e distalmente por espinitríquias gladiadas (Figura 10E). Ventosa apical 19-41,80 $(29,04 \pm 4,9, \mathrm{n}=117) \times 30,40-64,60(44,30 \pm 6,05, \mathrm{n}=117)$, coberta proximalmente por filitríquias aciculares $6-17 / \mu \mathrm{m}^{2}(11 \pm 3, \mathrm{n}=20), 0,37-0,58(0,46 \pm 0,05, \mathrm{n}=20)$ de comprimento, 0,09-0,11 $(0,10 \pm 0,01, \mathrm{n}=20)$ de largura na base (Figura 10F) e distalmente por espinitríquias gladiadas $1-3 / \mu m^{2}(2 \pm 1, n=30), 1,41-1,86(1,73 \pm 0,15, n=9)$ de comprimento, 0,52-0,69 (0,63 \pm $0,05, \mathrm{n}=9$ ) de largura na base, distribuídas entre filitríquias aciculares $6-8 / \mu \mathrm{m}^{2}(11 \pm 2, \mathrm{n}=5)$ (Figura 10G). Ganchos simétricos (Figura 9C), comprimento do gancho lateral cerca de 0,90 ( $\mathrm{n}=2$ ) o comprimento do gancho medial, furca emergindo lateralmente da região central da base, revestido por tecido epitelial coberto por filitríquias aciculares até sua extremidade (Figura $10 \mathrm{H}$ ). Ganchos laterais $54,79-55,87(55,33 \pm 0,76, \mathrm{n}=2)$ de comprimento, base 26,62-27,09 (26,86 $\pm 0,33, \mathrm{n}=2)$, furca 69,67-77,34 (73,51 $\pm 5,42, n=2)$, largura da furca 32,71-33,06 $(32,89 \pm 0,25, n=2)$, base da furca próxima à base do gancho 12,85-17,28 $(15,07 \pm 3,13, \mathrm{n}=2)$, inserção da furca a partir de 28 $32 \%(30 \pm 3, \mathrm{n}=2)$ da base. Ganchos mediais 50,77-65,40 (58,39 $\pm 4,24, \mathrm{n}=22)$ de comprimento, base 22,23-30,68 (26,27 $\pm 2,49, \mathrm{n}=22)$, furca 56,11-74,94 $(67,17 \pm 5,75, \mathrm{n}=22)$, largura da furca $25,30-36,35(30,74 \pm 3,15, \mathrm{n}=22)$, base da furca próxima à base do gancho 10,57-16,84 (13,07 \pm $1,74, n=22)$, inserção da furca a partir de $29-43 \%(35 \pm 4, n=22)$ da base. Região de crescimento 

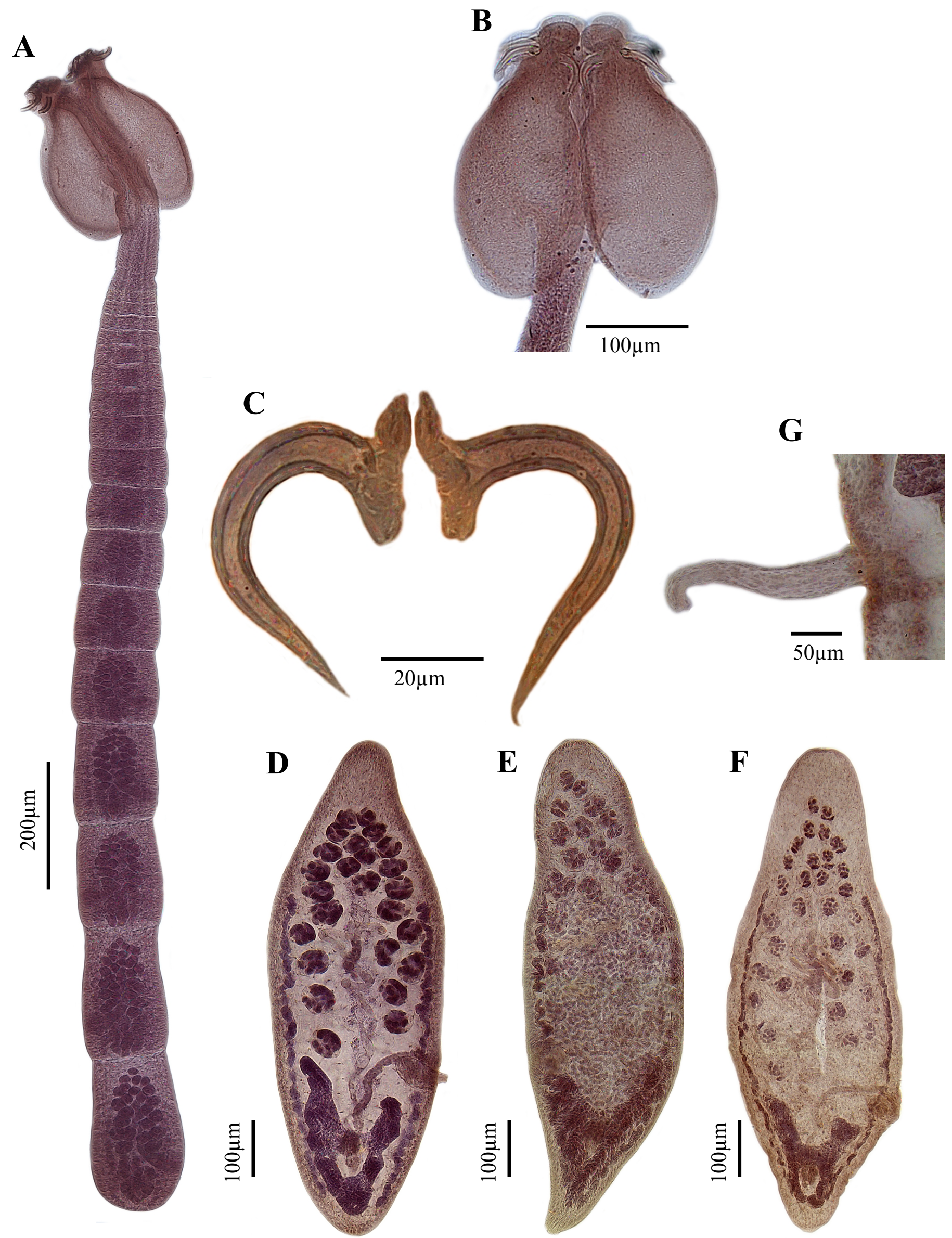

Figura 9. Potamotrygonocestus maurae. A. Espécime completo (MZUSP 7031); B. Escólex (MZUSP 7035); C. Ganchos (MZUSP 7028); D. Proglótide madura (MZUSP 7033); E. Proglótide grávida (MZUSP 7023); F. Proglótide pós grávida (MZUSP 7031); G. Cirro evertido (MZUSP 7027). 

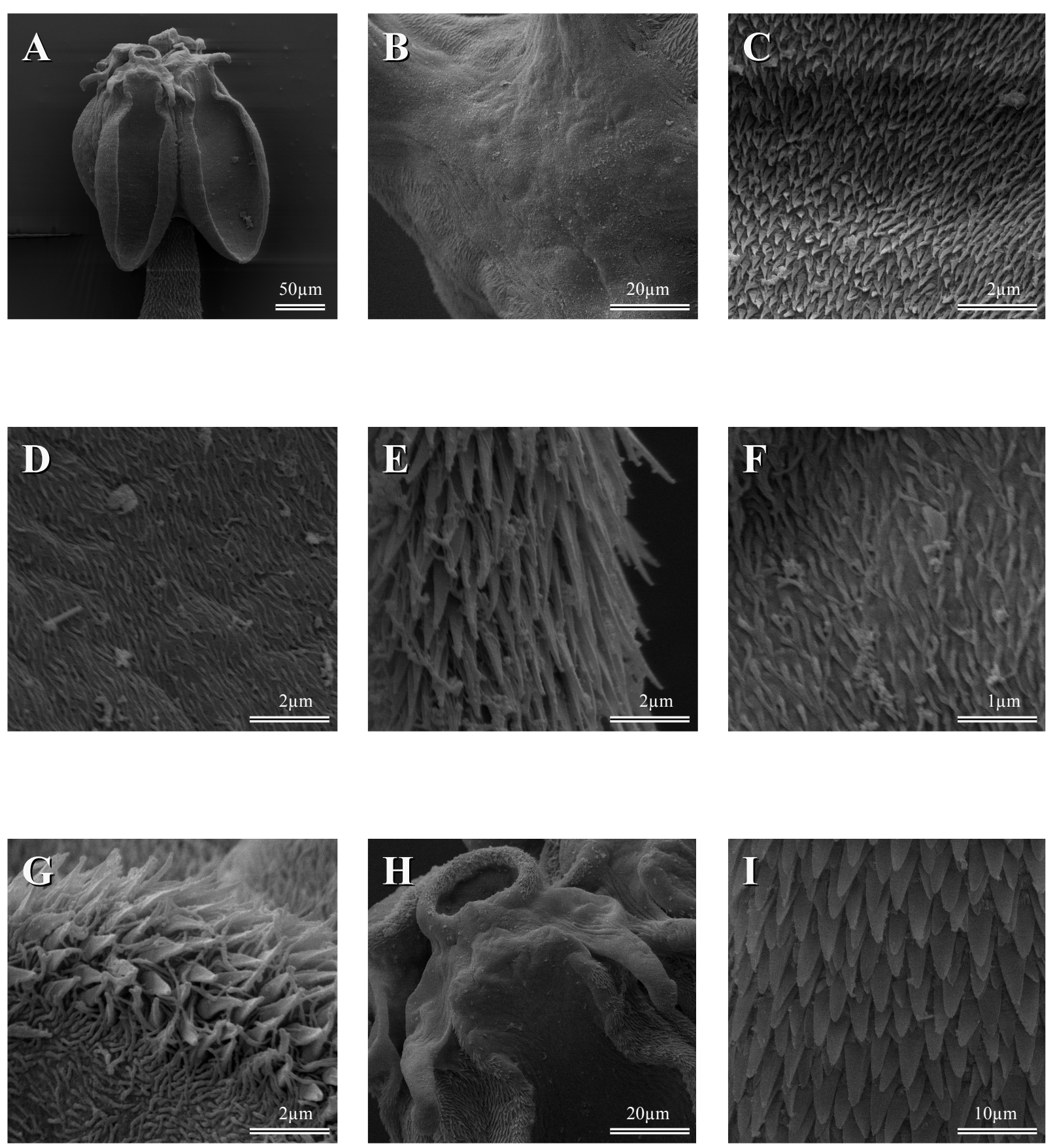

Figura 10. Potamotrygonocestus maurae. M.E.V. A: escólex. B: região apical da escólex. C: região proximal inferior do botrídeo. D: região proximal superior do botrídeo. E: região distal do botrídeo. F: região proximal da ventosa apical. G: região distal da ventosa apical. H: Ganchos. I: região de crescimento. 
coberta por espinitríquias gladiadas distribuídas entre filitríquias aciculares (Figura 10I); espinitríquias gladiadas $0-1 / \mu \mathrm{m}^{2}(\mathrm{n}=20), 6,81-9,33(8,09 \pm 0,86, \mathrm{n}=13)$ de comprimento, 2,77-3,86 $(3,29 \pm 0,40, \mathrm{n}=13)$ de largura na base.

Proglótides imaturas 140,94-649,89 (338,48 \pm 89,93, $\mathrm{n}=96) \times$ 86,13-274,05 (149,28 $\pm 33,52$, $\mathrm{n}=93)$; proglótides maduras não destacadas 313,20-665,55 (466,50 $\pm 93,39, \mathrm{n}=19)$ x 117,45250,56(191,22 $\pm 29,33, \mathrm{n}=19)$; proglótides maduras destacadas 422,82-1088,37 (737,76 \pm 158,65, $\mathrm{n}=36) \times 164,43-414,99(268,18 \pm 60,63, \mathrm{n}=36)$ (Figura 9D); proglótides grávidas 571,59-1761,75 $(1086,69 \pm 275,61, \mathrm{n}=56) \times 211,41-555,93(355,29 \pm 80,84, \mathrm{n}=56)$ (Figura 9E); proglótides pósgrávidas 712,53-1550,34 (1022,37 $\pm 346,26, n=7) \times 203,58-571,59(362,42 \pm 162,03 n=7)$ (Figura 9F). Testículos em duas colunas longitudinais anteriores ao ovário, terceira coluna intermediária anterior ao útero em proglótides imaturas e maduras; testículos 16-36 (24 \pm 4 , n=179) em número, 8-18 (12 $\pm 2, \mathrm{n}=179)$ poralmente, 8-20 (12 $\pm 2, \mathrm{n}=179)$ aporalmente; proglótides imaturas 12,20$65,88(28,48 \pm 8,35, \mathrm{n}=670) \times 12,20-80,52(37,56 \pm 9,36, \mathrm{n}=670)$; proglótides maduras não destacadas 21,96-61 $(38,86 \pm 8,08, \mathrm{n}=190) \times$ x 26,84-75,64 (47,98 $\pm 8,04, \mathrm{n}=190)$; proglótides maduras destacadas 31,72-87,84 (55,10 $\pm 11,21, \mathrm{n}=360)$ x 34,16-85,40 (54,25 $\pm 9,23, \mathrm{n}=360)$;

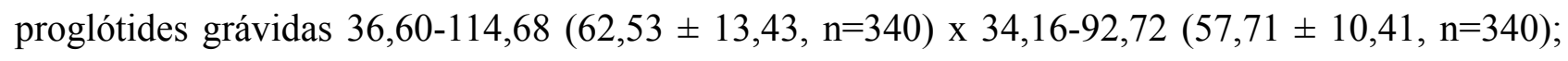
proglótides pós-grávidas $36,60-82,96(54,27 \pm 12,87, \mathrm{n}=50) \times 24,40-87,84(54,36 \pm 16, \mathrm{n}=50)$. Poro genital postero-lateral, átrio genital presente ou ausente (Figura 9G); 26-67\% (40 $\pm 8, n=63$ ) da margem posterior da proglótides imaturas não destacadas; 32-49\% (39 $\pm 4, \mathrm{n}=19)$ da margem posterior das proglótides maduras não destacadas; 19-61\% $(35 \pm 8, \mathrm{n}=35)$ da margem posterior das proglótides maduras destacadas; 11-55\% $(33 \pm 8, \mathrm{n}=46)$ da margem posterior das proglótides grávidas destacadas; 24-36\% $(32 \pm 5, \mathrm{n}=7)$ da margem posterior das proglótides pós grávidas destacadas. Vitelária em duas colunas laterais aos testículos, estendendo-se posteriormente ao ovário. Ovário na porção terminal da proglótide, em forma de A invertido (Figura 9D) ou H; proglótides imaturas 38-129,20 (68,59 \pm 18,26, $\mathrm{n}=78), 38-190(103,38 \pm 33,04, \mathrm{n}=78), 45,60-247$ $(116,97 \pm 37,97, \mathrm{n}=78)$; proglótides maduras não destacadas 49,40-121,60 (79,80 $\pm 18,44, \mathrm{n}=19)$, 79,80-190 (139 $\pm 32,43, \mathrm{n}=19), 98,80-212,80 \quad(156,60 \pm 35,43, \mathrm{n}=19)$; proglótides maduras destacadas 57-205,20 (124,84 $\pm 33,47, \mathrm{n}=34), 110,20-349,60(203,30 \pm 53,74, \mathrm{n}=34), 133-380$ $(228,56 \pm 54,63, \mathrm{n}=34)$; proglótides grávidas 98,80-247 (160,89 $\pm 32,55, \mathrm{n}=56), 125,40-539,60$ (286,70 $\pm 87,01, \mathrm{n}=56), 133-589(339,96 \pm 98,92, \mathrm{n}=56)$; proglótides pós-grávidas 114-224,20 $(151,46 \pm 41,19, n=7), 209-281,20(243,74 \pm 29,22, n=7), 235,60-349,60(287,17 \pm 37,86, n=7)$.

Hospedeiro tipo: Potamotrygon orbignyi (Castelnau, 1855).

Local de infecção: válvula espiral.

Localidade tipo: Praia do Defunto, Rio Negro, arredores de Barcelos, Amazonas, Brasil. 
Localidades adicionais: Rio Branco, a 4h da confluência com o Rio Negro; Rio Abacaxis, Comunidade Maroin, Borba, Amazonas (S 4० 16' 58.07", W 58 36' 42.48"); Rio Abacaxis, Comunidade Terra Preta, Borba, Amazonas (S 4 24' 34.20", W 58 39' 43.91"), Rio Abacaxis, Comunidade Camarão, Borba, Amazonas (S $4^{\circ} 16^{\prime}$ 8.40", W 58 39' 13.32"), Rio Negro, Paranã Zamula, Barcelos, Amazonas (S $0^{\circ} 52^{\prime} 11.28^{\prime \prime}$, W 62 46' 37.92"), Rio Negro, Boca do Rio Demeni, Barcelos, Amazonas (S $0^{\circ} 46^{\prime} 31.80^{\prime \prime}, \mathrm{W} 62^{\circ} 56^{\prime} 14.28^{\prime \prime}$ ), Rio Negro, Ilha de Mariana, Barcelos, Amazonas (S $0^{\circ} 45^{\prime}$ 29.87", W 62 59' 18.23"), Rio Negro, Lago do Boiador, Ilha do Comparsa, Barcelos, Amazonas (S $0^{\circ} 54^{\prime}$ 24.11",W 62 58' 21.72"), Rio Cuiuni, Praia do Curupira, Barcelos, Amazonas (S 0 46' 41.88",W 63 8' 10.32").

Hospedeiros adicionais: Potamotrygon humerosa Garman, 1913.

Material examinado: Holótipo MZUSP 5854; parátipos MZUSP 5855-5857. MZUSP 7022: 2 adult. imat., em $P$. humerosa (AM07-01), Rio Abacaxis, Borba, Com. Maroin, Amazonas, Brasil; lat: -4.2828, long: -58.6118; dat: 09/01/07; col: F.P.L. Marques e M. Cardoso Jr. MZUSP 7023: 28 adult. imat., 1 adult. incomp., 1 adult. mad., 14 progl. grav., 7 progl. mad., em P. humerosa (AM07-03), Rio Abacaxis, Borba, Com. Maroin, Amazonas, Brasil; lat: -4.2828, long: -58.6118; dat: 08/01/07; col: F.P.L. Marques e M. Cardoso Jr. MZUSP 7024: 1 adult. imat., 2 progl. mad., em $P$. humerosa (AM07-06), Rio Abacaxis, Borba, Com. Maroin, Amazonas, Brasil; lat: -4.2828, long: -58.6118; dat: 11/01/07; col: F.P.L. Marques e M. Cardoso Jr. MZUSP 7025: 4 adult., 12 adult. imat., 7 adult. mad., 16 progl. grav., 3 progl. mad., em P. humerosa (AM07-07), Rio Abacaxis, Borba, Com. Maroin, Amazonas, Brasil; lat: -4.2828, long: -58.6118; dat: 11/01/07; col: F.P.L. Marques e M. Cardoso Jr. MZUSP 7026: 2 adult. imat., 1 adult. mad., 2 progl. grav., em P. humerosa (AM07-08), Rio Abacaxis, Borba, Com. Maroin, Amazonas, Brasil; lat: -4.2828, long: -58.6118; dat: 12/01/07; col: F.P.L. Marques e M. Cardoso Jr. MZUSP 7027: 2 adult., 13 adult. imat., 10 adult. mad., 2 progl. grav., 6 progl. mad., em P. humerosa (AM07-16), Rio Abacaxis, Borba, Com. Camarão, Amazonas, Brasil; lat: -4.2690, long: -58.6537; dat: 14/01/07; col: F.P.L. Marques e M. Cardoso Jr. MZUSP 7028: 16 adult., 1 adult. grav., 18 adult. imat., 1 adult. mad., 3 progl. grav., 12 progl. mad., 4 progl. pgrav., em P. humerosa (AM07-17), Rio Abacaxis, Borba, Com. Camarão, Amazonas, Brasil; lat: -4.2690, long: -58.6537; dat: 14/01/07; col: F.P.L. Marques e M. Cardoso Jr. MZUSP 7029: 2 adult., 5 adult. imat., 1 estrobilo, em P. humerosa (AM07-18), Rio Abacaxis, Borba, Com. Maroin, Amazonas, Brasil; lat: -4.2828, long: -58.6118; dat: 15/01/07; col: F.P.L. Marques e M. Cardoso Jr. MZUSP 7030: 4 adult. imat., 9 progl. grav., em P. humerosa (AM07-21), Rio Abacaxis, Borba, Com. Maroin, Amazonas, Brasil; lat: -4.2828, long: -58.6118; dat: 26/01/07; col: F.P.L. Marques e M. Cardoso Jr. MZUSP 7031: 2 adult. imat., 1 progl. Pgrav., 1 progl. grav., 2 progl. mad., 1 progl. pgrav., em P. orbignyi (RN05-15), Rio Negro, Boca do Bafuana, Barcelos, Amazonas, Brasil; lat: -0.9067, long: -62.9727; dat: 24/01/05; col: M.V. Domingues, N.M. Luchetti e S. Mello. MZUSP 7032: 2 adult. imat., 2 progl. grav., 5 progl. mad., 1 progl. pgrav., em P. orbignyi (RN05-16), Rio Negro, Ilha do Comparsa, Barcelos, Amazonas, Brasil; lat: -0.9067, long: -62.9727; dat: 24/01/05; col: M.V. Domingues, N.M. Luchetti e S. Mello. MZUSP 7033: 1 adult. imat., 6 progl. grav., 3 progl. mad., em P. orbignyi (RN05-20), Rio Negro, Paranã da Genésia, Barcelos, Amazonas, Brasil; lat: -0.9067, long: -62.9727; dat: 24/01/05; col: M.V. Domingues, N.M. Luchetti e S. Mello. MZUSP 7034: 1 adult. incomp., 2 progl. grav., em P. orbignyi (RN05-41), Rio Negro, Molongozal, Barcelos, Amazonas, Brasil; lat: -0.9067, long: -62.9727; dat: 27/01/05; col: M.V. Domingues, N.M. Luchetti e S. Mello. MZUSP 7035: 1 adult. imat., 1 adult. incomp., 1 progl. grav., em P. orbignyi (RN05-57), Rio Negro, Molongozal, Barcelos, Amazonas, Brasil; lat: -0.9067, long: -62.9727; dat: 31/01/05; col: M.V. Domingues, N.M. Luchetti e S. Mello. MZUSP 7036: 2 adult. imat., 1 adult. mad., em P. orbignyi (RN05-70), Rio Negro, Rio Cuiuní, Praia do Curupira, Barcelos, Amazonas, Brasil; lat: -0.7783, long: -63.1362; dat: 02/02/05; col: M.V. Domingues, N.M. Luchetti e S. Mello. MZUSP 7037: 1 adult. imat., em P. orbignyi (RN05-72), Rio Negro, Rio Cuiuní, Praia do Curupira, Barcelos, Amazonas, Brasil; lat: -0.7783, long: -63.1362; dat: 02/02/05; col: M.V. Domingues, N.M. Luchetti e S. Mello.

\section{Considerações taxonômicas:}

A descrição de Potamotrygonocestus maurae por Marques et al. (2003) baseou-se em um número restrito de espécimes (um adulto imaturo, quatro adultos incompletos e três proglótides destacadas), coletados em apenas um espécime de hospedeiro. Apesar do restrito número amostral, os autores distinguiram estes indivíduos das demais linhagens por um caráter discreto exclusivo. De acordo com esses autores, em membros de P. maurae a distribuição da vitelária se estende além dos limites posteriores dos lobos ovarianos, ao passo que nas demais espécies do gênero até então 
reconhecidas, a distribuição da vitelária se estende posteriormente até no máximo ao nível do istmo ovariano. A diagnose da espécie a partir da distribuição da vitelária foi importante para a identificação dos espécimes coletados para este estudo quando comparados ao holótipo, pois espécime tipo de $P$. maurae não apresenta ganchos completos que permitam sua identificação. $\mathrm{O}$ gancho ilustrado por Marques et al. (2003: 389, Figura 10B), além de estar partido, encontra-se inclinado na preparação.

Além da distribuição da vitelária, P. maurae também pode ser identificado pela morfologia de seu gancho. Ganchos lateral e medial com furca apresentando simetria morfológica semelhante, variando no comprimento e ganchos lateral e medial com angulação na furca no nível da inserção na base e furca do gancho reta após a angulação, diminuindo sua largura distalmente. Os atributos morfométricos e merísticos de $P$. maurae apresentaram sobreposição com aqueles observados para P. magdalenensis e P. amazonensis (Anexo I), espécies com as quais P. maurae compartilha morfologia do gancho similar. Nestas espécies, a inserção da furca na base do gancho está centralizada. No entanto, embora similar, P. maurae difere de P. magdalenensis e P. amazonensis pela morfologia seu gancho lateral, que apresenta angulação e tem sua extremidade distal voltada para baixo (Figura 9C). Em P. magdalenensis (Figura 5C) e P. amazonensis (Figura 8C), o gancho lateral é arredondado e tem sua extremidade distal voltada para o centro da ventosa apical. Por fim, P. maurae difere de P. travassosi na posição de inserção da furca do gancho em sua base (região centro-lateral da base vs. postero-lateral (Figura 6C), respectivamente).

Os dados obtidos em M.E.V. para P. maurae mostram que a distribuição de microtríquias no escólex difere daquelas espécies para as quais há dados disponíveis (Anexo II). Potamotrygonocestus maurae possui apenas microtríquias do tipo filitríquias aciculares na região proximal da ventosa apical e do botrídeo, ao contrário das outras espécies que possuem espinitríquias gladiadas nestas regiões, interespaçadas ou não por filitríquias. Devido à indisponibilidade de espécimes com o cirro evertido, não foi possível avaliar se há diferenças também na distribuição de microtríquias sobre esta região. Estes dados indicam que a morfologia destas estruturas tegumentares pode ser útil taxonomicamente, porém só será possível confirmar esta utilidade quando todas as espécies de Potamotrygonocestus forem analisadas sob M.E.V..

Descrito originalmente como parasita de P. orbignyi no Rio Negro (AM), P. maurae foi encontrado também em P. humerosa no Rio Abacaxis (AM), indicando que a restrita especificidade parasita-hospedeiro creditada à espécie por Marques et al. (2003) deveu-se à baixa amostragem do táxon. A espécie foi coletada somente na região hidrográfica do Amazonas e foi encontrada convivendo com outra espécie de Potamotrygonocestus, P. amazonensis, e ambas apresentam a mesma distribuição geográfica. 